\title{
Does the stork deliver happiness? Parenthood and life satisfaction*
}

\author{
Gregori BaEtschmanN ${ }^{\dagger}$ \\ University of Bern
}

\author{
Kevin E. Staub ${ }^{\ddagger}$ \\ University of Melbourne \\ IZA, Bonn
}

\author{
RAPHAEL StUdeR ${ }^{\S}$ \\ University of Zurich
}

July 25, 2016

\begin{abstract}
This paper examines the relationship between parenthood and life satisfaction using longitudinal data on women from the German Socio-Economic Panel. Previous studies have focused on satisfaction differences between parents and ex-post similar childless adults or between pre- and post-birth years of mothers. Mostly small and often negative effects of parenthood are reported. Both comparisons are problematic if life satisfaction increases before giving birth; that is, if dynamic self-selection into parenthood exists. In this study we exploit the extended longitudinal dimension of the panel to track self-reported life satisfaction of women eventually to become mothers and of women eventually attaining a completed fertility of zero. In our estimations we employ matching and regression techniques which account for the selection into motherhood. We find motherhood to be associated with positive satisfaction gains occurring over several years.
\end{abstract}

Keywords: Happiness, subjective well-being, children, fertility, motherhood, parenthood, life cycle, selection, matching, fixed effects.

JEL classification: D10, J11, J12, J13.

\footnotetext{
*Acknowledgements: We thank the editor William Neilson, the associate editor Carol Graham, two anonymous referees, Jeff Borland, Arie Kapteyn, Giovanni Mastrobuoni, Nick Powdthavee, Andreas Steinhauer, Jenny Williams, Rainer Winkelmann and participants of the RAND Labor \& Population Brown Bag Seminar, the LMU Munich's Research Workshop in Empirical Economics, the $2^{\text {nd }}$ Zurich Workshop in Economics, the Research Seminar on Sociology in Bern, the Australian Conference for Economists in Hobart, and the International Panel Data Conference in Tokyo for comments. Kevin Staub acknowledges financial support from the Swiss National Science Foundation through grant PBZHP1-138692. This is a revised version of Working Paper No. 94 (October 2012), Department of Economics, University of Zurich.

${ }^{\dagger}$ University of Bern, Institute of Sociology, Fabrikstrasse 8, 3012 Bern, Switzerland. Phone: +41 316314874 . E-mail: gregori.baetschmann@soz.unibe.ch

${ }^{\ddagger}$ Corresponding author: The University of Melbourne, Department of Economics, 111 Barry Street, Carlton, VIC 3010, Australia. Phone: +61 3903 53776. E-mail: kevin.staub@unimelb.edu.au

${ }^{\S}$ University of Zurich, Department of Economics, Zuerichbergstrasse 14, 8032 Zuerich, Switzerland.
} 


\section{Introduction}

How does becoming a mother affect women's life cycle utility streams? Rational-choice approaches to fertility embedded in standard dynamic economic models of fertility assume that the net utility gain of motherhood is positive. In sharp contrast, the predominant view in the sociological and psychological literature is that there is a negative net effect of parenthood. This view is largely derived from the empirical literature on subjective well-being where the correlation between having children and life satisfaction is usually found to be negative. In this paper, we revisit the problem of estimating the effect of childbearing on life satisfaction using new estimation strategies. ${ }^{1}$

In the majority of previous studies, the control group for parents is represented by childless adults. Such a control group contains both individuals who will never have children and individuals who do not have children at present but who will be parents in the (near) future. The mixing of these two groups can lead to biased estimates if, for example, life satisfaction increases before having the first child. To overcome this problem of a censored parenthood status, we focus on women with completed fertility and compare two groups: mothers and non-mothers, i.e., women who finish their fertile years without having children. Taking advantage of a long panel with up to 26 yearly observations per individual, we use matching and regression techniques to compare the life satisfaction paths of mothers to the paths of similar non-mothers who displayed the same satisfaction paths than mothers before their first birth.

An alternative estimation approach in the literature are life event studies. This research strand is based on the idea of adaptation to an individual baseline satisfaction level: Life events such as transition into parenthood may temporarily disturb satisfaction away from the baseline level, but eventually satisfaction paths return to the baseline. Thus, here the implicit control group for parents are the same parents before they had their first child. The finding in this literature is that there is an anticipation period of about one year, a moderate positive effect during the year of birth, and an immediate return to the baseline (or even a dip slightly below the baseline) the year after. But to identify the effect correctly a key factor is to determine the appropriate baseline level. If the baseline level is estimated including a part of the satisfaction path which is already heightened due to anticipation, the resulting estimate of the baseline is too high leading to an underestimation of the effect. We study pre-birth satisfaction paths of mothers in detail, finding evidence that satisfaction starts increasing up to about five years before birth of the first child. To take this into account, in our second approach we contrast mothers' satisfaction paths to their past happiness levels five years before birth of the first child.

Thus, both our approaches differ from those in the literature in the use of alternate control groups which we believe can yield new insights into understanding the impact of motherhood on satisfaction. In particular, our empirical strategy focusses on dealing with dynamic selection into motherhood; that is, increasing life satisfaction before having the first child. This issue has been neglected so far in the literature and could help explain the small and negative effects reported in previous studies. Our results from both approaches, which include nearest-neighbor matching and regressions with and without fixed-effects, are similar. While they are broadly in line with the adaptation hypothesis suggested in

\footnotetext{
${ }^{1}$ Following the convention in economics, we use the words happiness, satisfaction and well-being as synonyms.
} 
previous life event studies, they also suggest that the effect might be considerably larger and adaptation considerably slower than previously believed. We estimate the effect of motherhood for every year from first pregnancy to twenty years after transition to motherhood, finding the satisfaction gain of mothers to be positive throughout. We find an effect on mother's life satisfaction during the year of first child's birth that is about two to three times as large as the ones typically reported in the literature. For the year after first birth, we too find a substantial effect of about $80 \%$ of the size of the effect during the year of birth. The effect remains positive and jointly statistically significant for the following ten years, although its magnitude for this period is more modest. We use the estimates to obtain a monetized net present worth of motherhood, finding the compensating variation of motherhood to lie roughly between one and two net yearly household incomes. Our results can be viewed as evidence suggestive of a net utility gain of motherhood, a finding consistent with rational-choice approaches to fertility.

The paper is organized as follows. The next section reviews previous work on life satisfaction and motherhood, and discusses the empirical approaches used in the literature in the context of the present research question. In Section 3 we investigate dynamic selection into motherhood by analyzing the satisfaction paths of mothers prior to their first delivery. Our methodological approaches tackling selection into motherhood are explained in Section 4. Section 5 contains our main regression results, and compares them to results obtained using traditional approaches. In Section 5 we also explore further aspects related to fertility and life satisfaction, such as the effects at different ages of first birth, the effect for single-child and multiple-parity mothers, and the effect among fathers. Section 6 contains a concluding discussion.

\section{Related literature}

\subsection{Life satisfaction and parenthood}

The last decade has seen a boom in the field of happiness economics with a diverse host of both theoretical and empirical contributions. Recent surveys of this literature can be found in Ferreri-Carbonell (2013), Blanchflower (2009), Layard (2005), Frey \& Stutzer (2002) and Kahneman et al. (1999). One reason for this growth has been the increasing evidence from economists and psychologists alike suggesting that individual responses on subjective well-being collected from surveys can be usefully interpreted as proxy measures for utility in a variety of contexts, its analysis thus allowing to provide (rough) estimates of the trade-offs guiding choice behavior. ${ }^{2}$ While the issue studied most intensely has been the relationship of income and employment to well-being, other aspects such as health, marriage and religion have also received due attention in the literature. In each of these cases, the existing research has been able to uncover clear satisfaction gains associated with these factors as would be expected from a mainstream view of utility. ${ }^{3}$

\footnotetext{
${ }^{2}$ An in-depth review on the literature linking subjective well-being to utility can be found in Clark et al. (2008b). See Benjamin et al. (2012) for a recent contribution.

${ }^{3}$ The seminal paper in the literature on income and happiness is Easterlin (1973); see Easterlin (2001) and Stevenson \& Wolfers (2008) for recent additions. For sources on the literature on unemployment we refer to Clark \& Oswald (1994)
} 
Fertility, by contrast, is an aspect which has received less direct attention in the happiness literature, at least relative to its important place in microeconomic theory and extensive body of accompanying empirical research dating back to Becker (1960) and Willis (1973). The predominant finding across numerous datasets is that individuals with children report on average lower satisfaction than comparable childless adults. This negative correlation is often interpreted as a negative net effect of parenthood. Two main rationalizations have been put forward to explain why most adults have children despite costs apparently outweighing benefits. The first explanation, common in the sociological literature, emphasizes the presence of pro-natal social norms which sanction disconformity (Morgan \& King, 2001; Vanassche et al., 2013). The second, psychological explanation sees the choice for having children as an instance of biased affective forecasting, i.e. individuals making rational decisions based on incorrect expectations (Gilbert, 2006) - in this case, based on the widespread belief expressed in surveys that having children brings happiness (Hansen, 2012). In the economic literature, the negative correlation is acknowledged regularly in survey articles (Blanchflower, 2009; Clark et al., 2008b; Dolan et al., 2008; Ferrer-i-Carbonell, 2013), and interpretations along the lines of the psychological and sociological research are not uncommon.

\subsection{Empirical frameworks used in the literature}

Much of what is known on the subject does not stem from studies focusing on fertility; rather it often comes from regression studies where fertility measures are used as controlling variables to avoid confounding a specific effect of interest (Di Tella et al., 2001, 2003; Alesina et al., 2004; Clark, 2007). Three frameworks have been used to study the effect of parenthood on life satisfaction: (i) cross-section and pooled panel regression models, (ii) panel models with fixed effects and (iii) event studies. By far the most common of these is the first framework. Recently, Stanca (2012) confirmed the presence of the negative parenthood effect using this standard happiness equation framework for over 90 countries. Herbst \& Ifcher (2015) closely scrutinize the negative effect obtained with this framework for US data, concluding that the magnitude of the effect has been decreasing in the last decades and that it is driven mainly by older parents. The negative effect has also been found using the second framework (e.g. Stutzer \& Frey, 2006). In the few instances where the association is found to be positive, it is usually small and insignificant (Clark \& Oswald, 2002). A variant of the fixed effect approach exploits variation within identical twins (Kohler et al., 2005) instead of within an individual over time. The third approach is life-event studies tracking parental satisfaction over a time window around the birth of a child (Myrskylä \& Margolis, 2014; Clark \& Georgellis, 2013; Frijters et al., 2011; Clark et al., 2008a). This approach is similar to the second in that it is based on a fixed effects regression. However it allows for non-constant effects before and after the event occurs and is thus more flexible (for example it allows for a diminishing effect after delivery). This research has concluded that parents adapt completely to the birth of a child after the year of delivery.

A common issue across the literature is that the "treatment" variables used do not map cleanly to and Winkelmann \& Winkelmann (1998). For contributions on the relationship between happiness and marriage, and happiness and health, see e.g. Stutzer \& Frey (2006) and Veenhoven (2008), respectively. 
"becoming a parent", our variable of interest (see Myrskylä \& Margolis, 2014, for an exception). The treatment variable is sometimes the number of children residing in the household (frameworks (i) and (ii)) and sometimes the birth of a child (frameworks (ii) and (iii)). Our "treatment" variable is being a parent, regardless if the child is currently residing in the household of the parents or not.

A second issue relates to the insight from standard dynamic economic models of fertility that other outcome variables such as income, partnership status and employment are endogenous to the fertility decision $^{4}$ and should therefore not be controlled for. These are mediator variables or channels through which parenthood affects life satisfaction. However, it is common practice in all three frameworks to report ceteris-paribus effects that hold these outcomes fixed, making them difficult to interpret for our purposes. These ceteris paribus effects represent an ex-post comparison of satisfaction between parents and individuals with no children at the same values of other outcomes, when optimally these outcomes will differ precisely as a consequence of the parenthood decision. ${ }^{5}$ Indeed, Herbst \& Ifcher (2015), who extensively assess the robustness of the traditional happiness-equation estimates of the parenthood effect, find that the estimates are quite sensitive to the inclusion of different sets of covariates, a typical result when conditioning on mediator variables which are part of the channels through which the effect runs. Thus, in our estimations we will exclude contemporaneous control variables and view differences in these as endogenous to the fertility decision.

The paper most closely related to ours in the literature is perhaps that of Myrskylä \& Margolis (2014), since it also uses GSOEP data, and looks at satisfaction before and after first birth over a long period of years. Both their paper and ours find substantial evidence for increasing satisfaction paths of prospective mothers before first birth. However, while their paper focusses on documenting satisfaction paths of mothers, our approach also includes comparisons to individuals who will remain childless. This makes it possible to study the divergence between the two groups before first birth, and, therefore, dynamic selection into motherhood. Our paper is the first to discuss the implications of such a pre-birth divergence for estimates from the literature - i.e., if and how the presence of such a pre-birth selection biases conventional estimates of satisfaction gains-, and it develops new empirical strategies tailored to obtaining better estimates of satisfaction gains in the presence of such a dynamic selection.

Thus, in this study, we provide alternate estimates of the motherhood effect by tackling selection not only based on observables, as in framework (i), and time-invariant unobservables, as in frameworks (ii) and (iii), but also based on time-variant unobservables, i.e., dynamic selection. Building from the literature discussed above, we develop approaches which encompass the most suitable aspects from previous studies but address the issue of dynamic selection. To do this properly, we need to first investigate selection into parenthood in some detail.

\footnotetext{
${ }^{4}$ Arroyo \& Zhang (1997) provide an overview of the early dynamic fertility model literature; for an example of contemporary research encompassing occupational choice, marriage and fertility, see Ma (2010). Recent studies focusing explicitly on motherhood are surveyed in Del Boca \& Locatelli (2006), see also Wilde et al. (2010) and Michaud \& Tatsiramos (2011).

${ }^{5}$ Figure $\mathrm{C} 1$ in the Appendix illustrates this point by plotting working hours over the life cycle for women remaining childless and mothers with age at first birth 28.
} 
Figure 1: Life SATiSfaCtion Over the LifE CYCle

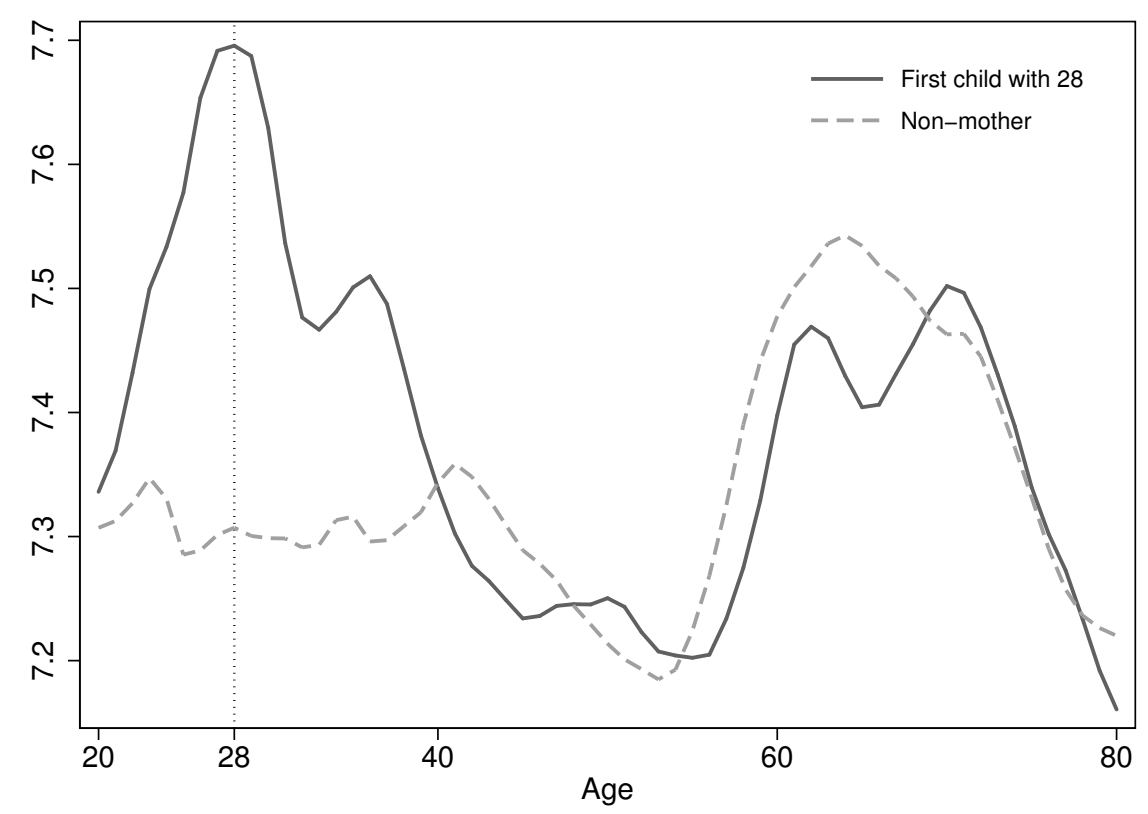

Notes: Data from the GSOEP waves 1984-2009, as detailed in Appendix A1. Displayed average life satisfaction paths are conditional on sets of dummies for survey years and years in panel, smoothed (Lowess) with bandwidth 0.12 .

\section{Self-selection into motherhood}

We use data on women from the German Socio-Economic Panel (GSOEP) 1984-2009. A number of features makes this survey especially amenable to our analysis of selection into motherhood. Data on dates of birth and interview can be used to construct exact ages for children and avoids having to round them to whole years. This makes it possible to precisely estimate mothers' happiness trajectories at a monthly level, which in turn enables us to identify, for instance, the happiness gains of the ninemonth pregnancy period. Additional information on whether the pregnancy was planned or unplanned is available for mothers that gave birth after 2002. The extended time dimension of the panel (we use twenty-five years in total) allows us to observe long periods of women's lives. In particular, we are able to identify women who later end up with a completed fertility of zero and study their satisfaction including the period of their fertile years. We define fertility as completed by age $41 .{ }^{6}$ Life satisfaction is assessed with the following question: "In conclusion, we would like to ask you about your satisfaction with your life in general. Please answer according to the following scale: 0 means completely dissatisfied, 10 means completely satisfied. How satisfied are you with your life, all things considered?" It is the standard measure for well-being in the literature, which simplifies the comparison of our results to the ones of other studies.

For instance, Figure 1 plots the average satisfaction path of such non-mothers (dashed line). Their life satisfaction decreases until about the age of 55 , and increases afterwards. ${ }^{7}$ The solid line plots satisfac-

\footnotetext{
${ }^{6}$ In our data, 99.8 percent of all mothers had given birth by that age.

${ }^{7}$ Such U-shapes of satisfaction-age curves are common in the literature, cf. Van Landeghem (2012) and Wunder et al. (2013) for recent overviews.
} 
tion of mothers delivering their first child at age 28. Mothers' life satisfaction shows a pronounced peak around the year of first child's birth. Such an evolution of the satisfaction path around birth is typical for mothers, also with other ages at first birth. The peak would be blurred, however, if the average satisfaction path for mothers with different ages at first birth was plotted. Figure 1 also reveals that satisfaction paths are similar after the age of 40 for mothers and non-mothers. Importantly, mothers' satisfaction path in Figure 1 is also clearly above non-mothers' path both before and after transition into motherhood. While in this raw contrast the positive difference after first birth hints at possible satisfaction gains of motherhood, the pre-birth period suggest that mothers differ from non-mothers already before they deliver their first child, and that this difference is not constant over time.

With this suggestive evidence in mind, we now consider a more rigorous analysis of the pre-birth period to examine whether there is positive or negative selection on unobservable qualities conditional on observable characteristics. Again, we focus on women with observed completed fertility. To identify the evolution before first birth precisely, we use information on the month of first child's birth and the months in which prospective mothers were surveyed in the years prior to first birth. This allows us to compute time to first birth in months. Details on the data are given in Appendix A2. We regress self-reported life satisfaction on indicators of number of months to first birth and control variables:

$$
l s_{i t}=\alpha+\text { months to } \operatorname{birth}_{i t}^{\prime} \boldsymbol{\beta}+\mathbf{a g e}_{i t}^{\prime} \boldsymbol{\gamma}+\mathbf{x}_{i t}^{\prime} \boldsymbol{\delta}+\varepsilon_{i t},
$$

where $l s_{i t}$ is life satisfaction for individual $i$ in wave $t$ on the 11-point Likert scale. The vector

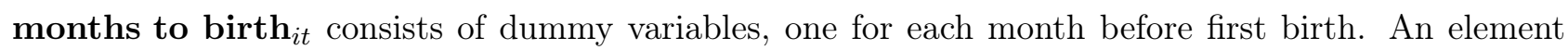
takes the value one if a mother was surveyed during that specific month before birth of her first kid. All elements of months to birth $_{i t}$ are equal to 0 for non-mothers. The regression controls for age with a full set of dummy variables, which are collected in the vector $\mathbf{a g e}_{i t}$. Accounting flexibly for age is indispensable in the context of fertility. The vector $\mathbf{x}_{i t}$ includes further control variables. ${ }^{8}$ The variable $\varepsilon_{i t}$ is the regression error.

Figure 2 visualizes the estimates of the parameters of interest in model (1) for the last seven years before first birth. The solid line shows average predicted life satisfaction for mothers. The dashed and dotted lines depict predicted life satisfaction for non-mothers using the covariate distribution of mothers. The regressions represented by the dashed and dotted lines differ by the number of included control variables. Whereas the former only controls, beside age, for survey year and years in panel, the regression of the dotted line also controls for the full set of socioeconomic controls. There is little difference between mothers' and non-mothers' life satisfaction until five years before birth. From that point on mothers' satisfaction increases steadily. The growth of the satisfaction path steepens around one year before birth. Women surveyed in the month before birth of their first child report on average a one point higher life satisfaction than comparable non-mothers. ${ }^{9}$

\footnotetext{
${ }^{8}$ The further control variables are: survey year, number of years in panel, education, relationship status, household members, working hours and household income. We do not control for the seasonality of births, as the average number of daily births is equally distributed over months in Germany (Statistisches Bundesamt, 2012). Appendix A0 contains a detailed description of the included terms.

${ }^{9}$ The lines plotted in Figure 2 have been smoothed, which makes the effect appear smaller.
} 


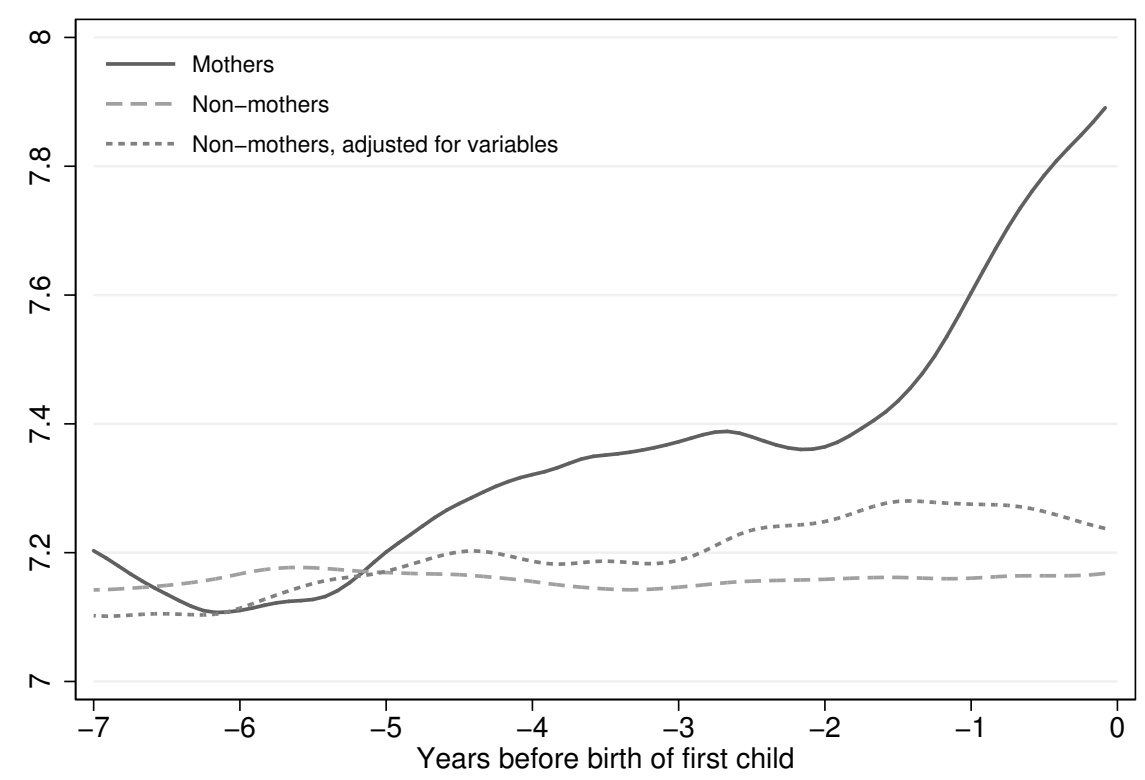

Notes: The graph depicts parameter estimates for the vector of dummy variables months to birth in model (1) for a subset of 7 years. The data is detailed in Appendix A2. Displayed average life satisfaction paths are conditional on a full set of dummies for age, survey years and years in panel. Predicted life satisfaction adjusted for variables further includes controls for education, relationship status, household members, working hours and household income. All lines smoothed (Lowess) with bandwidth 0.3. Appendix A0 contains a detailed description of the included terms.

The gradual increase in mothers' satisfaction could be the result of positive life events which are conducive to the decision to start a family such as partnership, increased household income, etc. To explore this issue, Figure 3 plots estimates from models akin to equation (1) but for different dependent variables. The top left panel shows the pre-birth path of marriage status. Mothers experience a steep increase in marriage rates while non-mothers' rates only increase slightly. When considering partnership more broadly, however, as in the top right panel, we see that there is also a substantial positive trend in the share of non-mothers who are in a relationship. Nevertheless, the path of mothers diverges from that of non-mothers around year -5 , the same time as the life satisfaction paths. The bottom panels show two variables related to economic status: household income and weekly working hours. While household income of mothers is higher than that of non-mothers, and both groups experience steady increases over the period, no divergence between the groups is visible. On the other hand, weekly working hours for mothers are initially lower than those of non-mothers, but the gap closes during the period of life satisfaction divergence. In the month immediately before child birth the gap widens again drastically.

Figure 3 suggests that the paths of important socioeconomic indicators are correlated to the life satisfaction paths. However, the socioeconomic variables in $\mathbf{x}_{i t}$ of equation (1), which control for these exact paths, only explain a small part of the satisfaction gap before first birth, as the dotted line in Figure 2 shows. This indicates the presence of substantial positive selection on unobservables. For instance, mothers' satisfaction increase over non-mothers may be related to aspects of the socioeconomic variables which are difficult to measure, such as the quality of the partnership or marriage. The 

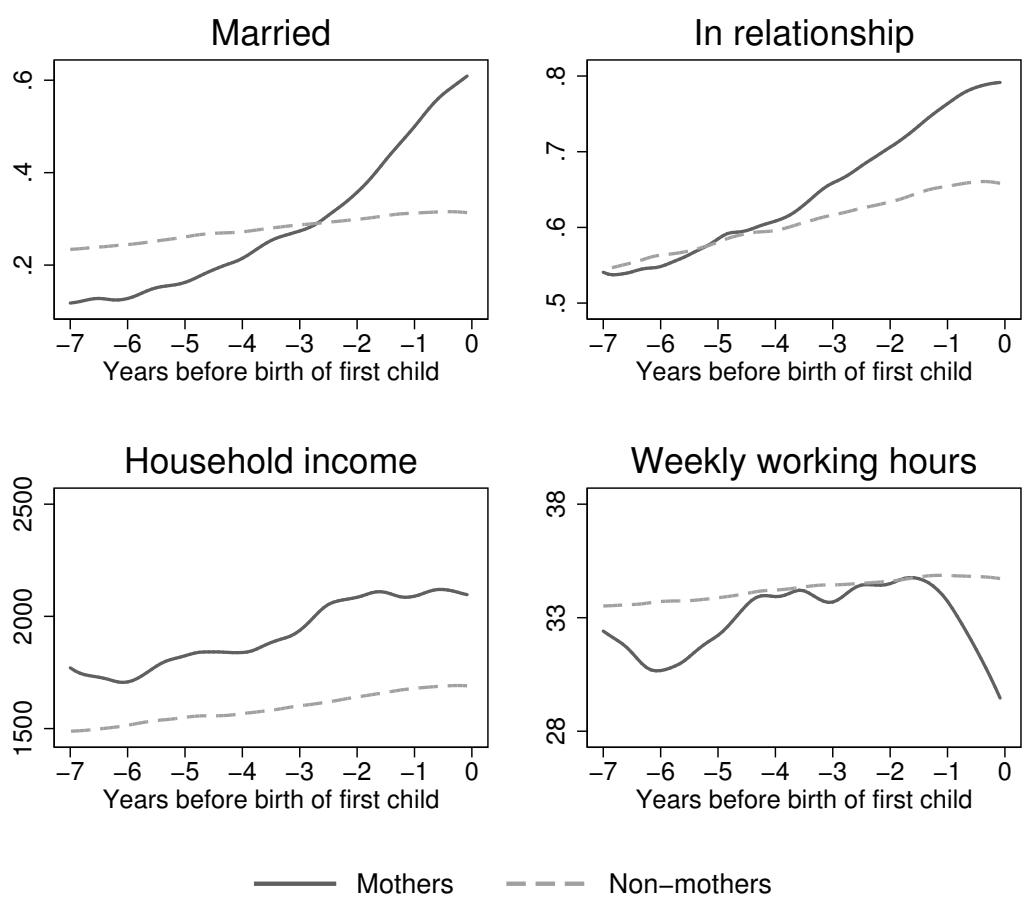

\begin{abstract}
Notes: The graph depicts parameter estimates for the vector of dummy variables months to birth in a model similar to (1) but with dependent variables as indicated in the graph titles instead of life satisfaction: Married (=1 if married), in relationship $(=1$ if married or in a stable relationship), household income, and weekly working hours. The data is detailed in Appendix A2. Displayed average paths are conditional on a full set of dummies for age, survey years and years in panel. All lines smoothed (Lowess) with bandwidth 0.3 .
\end{abstract}

empirical strategies that we develop in the next section account for precisely such dynamic differences in unobservables.

Table 1 contains regression results which confirm the stylized facts visible from Figure 2 using raw numbers. The estimates correspond again to model (1), but the large number of monthly indicators has been collapsed into three periods: pregnancy, from pregnancy to five years before first birth (called "anticipation period" in the table), and before five years. ${ }^{10}$ Mothers and non-mothers start out having virtually the same expected happiness, indicating that the selection into motherhood is not driven by permanent, time-invariant characteristics. Column 1 suggests a substantial, statistically significant difference in life satisfaction between mothers and non-mothers in the 5 years before birth. Once we control for all possible characteristics, the average difference in life satisfaction over these years decreases somewhat but remains large. Moreover, pregnancy is characterized by large statistically significant satisfaction gains in both regressions. ${ }^{11}$

To investigate further whether these differences really stem from future parenting, we use information on planned and unplanned pregnancies which is available for a subsample of the GSOEP, and replicate

\footnotetext{
${ }^{10}$ The last period goes beyond the limit of seven years shown in Figure 2. The earliest observations are up to 20 years before first birth. However, the number of observations diminishes very fast with increasing time to first birth.

${ }^{11}$ We also replicated these estimations using yearly birth data and obtained very similar results.
} 
Table 1: OLS estimates of SATisfaction Differences BetWeen PRospective mothers And NON-MOTHERS

\begin{tabular}{|c|c|c|}
\hline & (1) & $(2)$ \\
\hline \multirow[t]{2}{*}{ Pregnancy (9 months to 1 month before birth) } & $0.71^{* * *}$ & $0.65^{* * *}$ \\
\hline & $(0.12)$ & $(0.12)$ \\
\hline \multirow[t]{2}{*}{ Anticipation period (next 4 years) } & $0.26^{* *}$ & $0.18^{*}$ \\
\hline & $(0.12)$ & $(0.11)$ \\
\hline \multirow[t]{2}{*}{ More than 5 years before birth } & 0.01 & 0.04 \\
\hline & $(0.16)$ & $(0.15)$ \\
\hline Socioeconomic control variables & No & Yes \\
\hline Number of observations & \multicolumn{2}{|c|}{5,756} \\
\hline Number of individuals & \multicolumn{2}{|c|}{947} \\
\hline \multicolumn{3}{|c|}{$\begin{array}{l}\text { Notes: Cluster-robust standard errors in parenthesis. }{ }^{* * *},{ }^{* *} \text {, and }{ }^{*} \text { indicate statis- } \\
\text { tical significance at } 1 \%, 5 \% \text { and } 10 \% \text {. Both regressions include a full set of dummies } \\
\text { for age, survey years and years in panel. The regression in column }(2) \text { addition- } \\
\text { ally includes control variables for education, relationship status, household members, } \\
\text { working hours and household income. Appendix A0 contains a detailed description } \\
\text { of the included terms. }\end{array}$} \\
\hline
\end{tabular}

Figure 2. ${ }^{12}$ The vector containing months to first birth is interacted with an indicator whether the pregnancy was planned or not. Figure 4 plots the results. Mothers with planned pregnancies - the large majority - exhibit the same increasing trend as before. Mothers with unplanned pregnancies have lower average satisfaction. The path is also more volatile, but this might be a consequence of the small sample size. Up to the pregnancy period, there is little evidence for a trend in their satisfaction. This strongly suggests that family planning is associated with increases in life satisfaction. However, the evolution of life satisfaction during unplanned pregnancies mirrors that of planned pregnancies.

Since the pregnancy effect is present in unplanned motherhoods and similar to that of planned motherhoods, we will treat it as part of the satisfaction gains due to motherhood. In contrast, we view the satisfaction differences in the period five years before first birth up to pregnancy as the result of positive dynamic selection on unobservables which we seek to account for directly in our estimations.

To gauge the extent of heterogeneity of the pre-birth satisfaction divergence, we conclude this section by briefly reporting on a subsample analysis, whose results are depicted in Figure $\mathrm{C} 2$ in the appendix. We disaggregated the pre-birth life satisfaction paths by early human capital investment levels, as captured by the type of secondary schooling degree completed (the German education system is characterised by early and strict tracking of students into different streams). We focus on early human capital as, in contrast to other potentially interesting variables, it is constant over the whole period for the vast majority of women in the sample, thus facilitating a meaningful stratification. Early human capital is especially relevant in our case as it can be seen as reflecting cognitive and non-cognitive abilities that might be strongly related to family planning, and thus to the pre-birth satisfaction path.

\footnotetext{
${ }^{12}$ The women in this subsample are from younger cohorts. For further details refer to Appendix A3.
} 


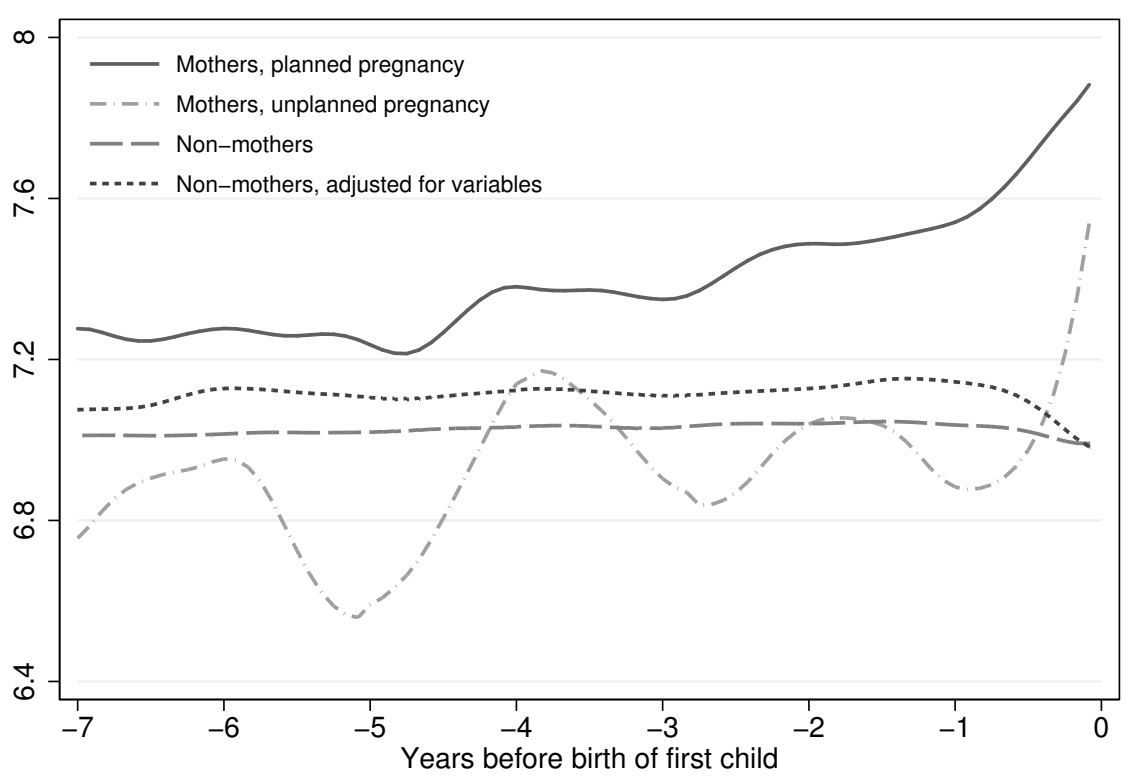

Notes: The graph depicts parameter estimates for the vector of dummy variables months to birth in model (1) interacted with a dummy indicating whether motherhood was planned or not, for a subset of 7 years. The data is detailed in Appendix A3. Displayed average life satisfaction paths are conditional on a full set of dummies for age, survey years and years in panel. Predicted life satisfaction adjusted for variables further includes controls for education, relationship status, household members, working hours and household income. All lines smoothed (Lowess) with bandwidth 0.3. Appendix A0 contains a detailed description of the included terms.

High early human capital includes, among other benefits, the option value of applying for universities and/or technical/vocational colleges, and is therefore also an important indicator of future educational attainment and of future economic success. Our results show that mothers' divergence is greater and starts earlier among women with high human capital, while it is smaller and starts between 2 to 3 years before birth among women with low human capital. Such a result could be brought about, for instance, by human capital amplifying the satisfaction returns from positive pre-birth life events, or by human capital affecting the 'arrival rate' of positive pre-birth life events. To address this heterogeneity in the pre-birth selection, the empirical strategies we present in the next section either treat the selection as individual-specific (first approach), or they treat the selection period as of a constant length, but use a conservatively long period (second approach).

\section{Empirical strategy}

What are the implications of the positive dynamic selection found in the previous section for the three frameworks used in the literature? The cross-sectional framework (i) should be the one most affected. Since in Germany more than $80 \%$ of all women give birth to at least one child (Statistisches Bundesamt, 2012) most of the individuals observed without children in the data are on their way of becoming parents. Prospective parents are censored in cross-section regressions and coded as nonparents. The combination of systematic censoring and positive dynamic self-selection of prospective 
mothers leads to average satisfaction levels of childless adults that are overestimated.

The panel fixed effect framework (ii) and the life event framework (iii) do not suffer from this censoring as they rely on comparing pre- and post-birth satisfaction levels of mothers. However, the baseline level or fixed effect, which is the average satisfaction before birth (possibly after factoring out the effect of covariates) will include the heightened anticipation pre-birth satisfaction. Therefore, the estimated baseline level is too high, inducing a downward bias in the motherhood effect. This issue is especially accentuated in life event studies which use a time window of only two to four years around the event "birth of a child", implying that the baseline is estimated using only the period where positive dynamic self-selection is acting.

We propose two different empirical approaches that embed the increase in life satisfaction during the five years prior to first birth. The first approach is related to framework (i) in that it relies on comparisons between individuals, while the second approach is related to frameworks (ii) and (iii) in that it relies on within-individuals comparisons. The two approaches we propose differ in more than the source of the variation they draw on (between vs within individuals). The first approach contrasts the life satisfaction trajectory of prospective mothers with the trajectory of comparable nonmothers. Crucially, "comparable" means here (beyond having the same observable socio-economic characteristics) that non-mothers' satisfaction trajectory underwent the same (increasing) path that we found for mothers in their "anticipation period". We implement this approach in two ways: with a nearest neighbor matching estimator that pairs mothers to the most similar non-mothers in terms of pre-birth covariates and pre-birth life satisfaction, and with a regression which controls for pre-birth covariates and the average pre-birth life satisfaction trend and level.

The second empirical strategy is to perform within-individuals before-after comparisons of satisfaction, but excluding from the "before" period the years in which the positive dynamic selection is present. The simplest implementation of this strategy is via a fixed effect regression with dummy variables for the last five pre-birth years. Thus, both approaches preclude self-selection of mothers from affecting the estimation of the motherhood effect. However, they account for self-selection in different ways. The first approach conditions on the self-selection while the second doesn't take it into account for estimating the baseline satisfaction level. For both approaches the yearly effects can be estimated for the pregnancy period and the first twenty years following birth. While the analysis is restricted to this window owing to the requirement to observe mothers five years before first birth, Figure 1 suggested that satisfaction paths of mothers and non-mothers converge in later years anyhow.

\subsection{First approach: Comparing mothers to similar non-mothers}

\section{Matching on past life satisfaction levels}

We employ the nearest-neighbor matching estimator proposed by Abadie \& Imbens (2002); see also Abadie et al. (2004). We match mothers and non-mothers based on age at first birth, life satisfaction during five, four, three and two years before birth and values of socioeconomic covariates in the year 
before birth. ${ }^{13}$ There are no exact matches over the whole set of conditioning variables, and we match exactly on past life satisfaction paths while using the four nearest matches in terms of Mahalanobi distance for the remaining variables. ${ }^{14}$ For instance, take a mother who had her first child with 25 . First we identified all non-mothers which had the same life satisfaction trajectories as the mother in the years 20 to 23 . Second, we choose from this group the four non-mothers with the most similar socioeconomic variables. The socioeconomic variables are measured at age 24 . Non-mothers can be used to match various ages of first birth. In the previous example, the same non-mother can serve as a match to a mother with age 34 at first birth. In that case, non-mother's covariates are measured at age 33 and past life satisfaction is measured from age 29 to 32 .

For every age of the first born child $p=-1,0,1,2, \ldots 20$, the matching estimator of the motherhood satisfaction effect reads:

$$
\beta_{p}=\frac{1}{N_{p}} \sum_{i=1}^{N_{p}} l s_{i p}-\widehat{l s}_{i p} .
$$

The variable $\widehat{l s}_{i p}$ denotes the counterfactual; that is, mother $i p$ 's predicted life satisfaction if she would not have a child. It equals $\frac{1}{4} \sum_{j \in J_{i}}^{4} l s_{j p}$, where $J_{i}$ is the set of the four most similar individuals to mother $i$ from the group of non-mothers. $N_{p}$ is the number of mothers observed $p$ years after first delivery. Thus, the effect (2) can be interpreted as the average treatment effect on the treated for the "treatment" motherhood.

\section{Regression using past life satisfaction levels and trends}

Similar in spirit to the matching estimator, this regression contrasts mothers and non-mothers conditioning on pre-birth satisfaction levels and trends. Non-mothers were assigned to all possible ages of first birth in order to determine "pre-birth" realizations of their covariates and "post-birth" satisfaction. The regression equation is

$$
l s_{i t}=\alpha+m_{i} \cdot \mathbf{y a b}_{i t}^{\prime} \boldsymbol{\beta}+\mathbf{y a b}_{i t}^{\prime} \boldsymbol{\gamma}+\theta_{1} \operatorname{avg}(p l s)_{i}+\theta_{2} \operatorname{tr}(p l s)_{i}+\mathbf{x}_{i t}^{\prime} \boldsymbol{\delta}+\varepsilon_{i t} .
$$

The variable $m_{i}$ is an indicator that equals one for mothers and zero for non-mothers. The vector $\mathbf{y a b}_{i t}$ contains a set of dummy variables for "years after first birth" ranging from -1 to 20 . The motherhood variable $m_{i}$ is interacted with $\mathbf{y a b}_{i t}$. Thus, mothers' satisfaction path relative to non-mothers during

\footnotetext{
${ }^{13}$ We use the same socioeconomic variables as before: relationship status, working hours, education, household members, household income. In addition we match on survey wave and years in panel.

${ }^{14}$ Details on the dataset are discussed in Appendix A4. Mahalanobi distance is the Euclidean distance between all matching variables weighted by their inverse covariance matrix (cf. Abadie \& Imbens, 2002). Our results are robust to the use of other number of nearest neighbors, such as the single nearest, two and six nearest neighbors. We used the software documented in Abadie et al. (2004): When no exact matches are found for variables where exact matches are attempted, nearest matches are taken for these variables but given a weight of 1,000 relative to the weight given to other matching variables. In our estimations, about $49.6 \%$ of exact matches were found for the past life satisfaction variables, improving the balance for these variables, on average, by about $86.9 \%$.
} 
pregnancy and the next twenty years is captured by the vector $\boldsymbol{\beta}$. The variables avg $(p l s)_{i}$ and $\operatorname{tr}(p l s)_{i}$ control for pre-birth differences in satisfaction two to five years before birth; avg $(\mathrm{pls})_{i}$ is the average past life satisfaction level and $\operatorname{tr}(p l s)_{i}$ — $t r$ stands for trend - is the average yearly change in satisfaction. The vector $\mathbf{x}_{i t}$ contains all socioeconomic covariates one year before birth as well as survey year and number of interviews. ${ }^{15}$ Such an analysis places heavy demands on the data. Mothers have to be observed before and after pregnancy to be included in the estimation sample and non-mothers before and after the assigned year of pregnancy. ${ }^{16}$

\subsection{Second approach: Comparing mothers' post-delivery satisfaction to their pre- anticipation satisfaction}

In contrast to the first two estimation strategies the fixed effects regression exploits only intrapersonal variation to identify the effect of motherhood. The fixed effect estimator is attractive as it enables to control for time-invariant individual-specific unobserved heterogeneity, such as personality traits. Moreover, rather than relying on a contrast between two non-randomly selected groups from the population, this approach estimates the effect of motherhood by contrasting mothers' life satisfaction after birth to before birth realizations. Such an estimation needs to carefully account for the dynamic selection into motherhood.

We implement the following specification:

$$
l s_{i t}=\alpha_{i}+\mathbf{a f c}_{i t}^{\prime} \boldsymbol{\beta}+\mathbf{a g e}_{i t}^{\prime} \gamma+\mathbf{p r e}_{i t}^{\prime} \theta+\mathbf{x}_{i t}^{\prime} \boldsymbol{\delta}+\varepsilon_{i t}
$$

The vector $\mathbf{a f c}_{i t}$ contains a set of dummy variables for "age of first child" ranging from -1 to 20. All elements of $\mathbf{a f c} \mathbf{c}_{i t}$ are zero for non-mothers; i.e. non-mothers only contribute to the identification of the parameters of other covariates. Pre-birth covariates and controls for pre-birth satisfaction paths are missing because parameters of time invariant variables are not identified anymore (reducing $\mathbf{x}_{i t}$ to controls for survey year and years in panel). They are absorbed into the fixed effects $\alpha_{i}$. In order to account for the heightened levels of satisfaction during the five years preceeding birth, i.e. to avoid overestimation of individual fixed effects, a set of four dummy variables is included in the regression $\left(\mathbf{p r e}_{i t}\right)$, indicating each of mothers' four years of the anticipation period before pregnancy. ${ }^{17}$

Out of the three models (2), (3) and (4), the fixed effect regression (4) is the least demanding on data. All observations, no matter how long in the sample and whether observed before or after birth can be used to identify at least part of the motherhood effect's dynamics, resulting in a visibly increased sample size. ${ }^{18}$

\footnotetext{
${ }^{15}$ Robustness checks were performed lagging covariates three and five years, producing virtually no changes in the results.

${ }^{16}$ The resulting dataset is described in Appendix A4. Replacing average level and average trend with satisfaction lags as in the matching approach reduces the estimation sample further. Our results are robust to such a specification, too.

${ }^{17}$ For non-mothers, all elements of pre $_{i t}$ are equal to zero.

${ }^{18}$ The data is detailed in Appendix A5.
} 


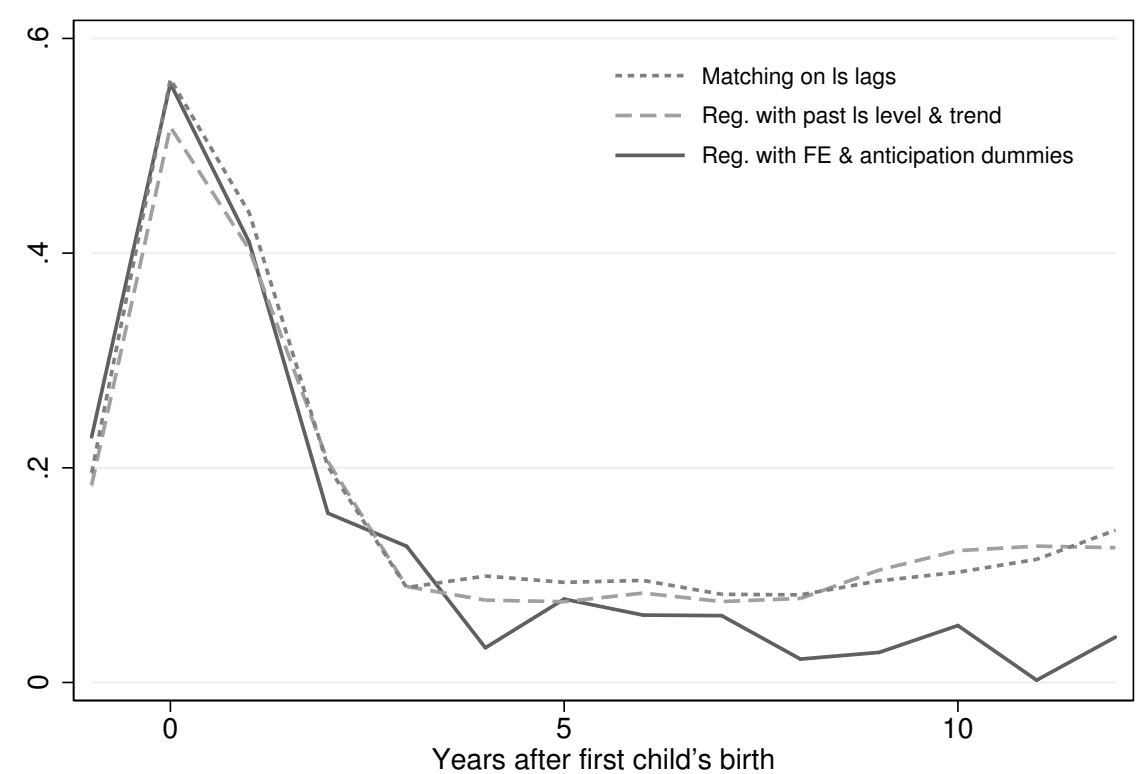

Notes: Matching estimates correspond to $\beta_{p}$ in model (2) using the data detailed in Appendix A4. Matching is achieved on past satisfaction levels from minus two to minus five years and other lagged covariates. Regression with past life satisfaction level and trend correspond to the estimates of $\beta$ in model (3). The regression uses the same data as the matching approach. It controls, besides other covariates, for average happiness level two to four years before delivery and the average change in the yearly happiness level in the same period. Fixed effect estimates correspond to $\beta$ in model (4). The estimation includes four extra dummies for minus two to minus five years before first birth and employs the data introduced in Appendix A5. Matching and reg. with past ls level \& trend lines smoothed (Lowess) with bandwidth 0.15 .

\section{$5 \quad$ Results}

\subsection{Main results}

Figure 5 presents results for the three approaches (2)-(4) discussed in Section 4, showing the estimated effects of motherhood for the year before birth of the first child and for the following twelve years. The effect of fatherhood is discussed in Section 5.3. The solid line depicts the results of the fixed effects estimation (4). The dashed and the dotted line show the results of the regression with past satisfaction level and trend (3) and the results of the matching approach (2). An effect in the order of one third of a point five years after first child's birth, for example, describes an average life satisfaction difference between mothers and non-mothers of 0.3 points on the 11-point scale. The entire set of point estimates for the period of 20 years after first child's birth, the corresponding standard errors, and more details on the regressions can be found in Table B1 in Appendix B.

Even though the strategies differ in the identification of the effect of motherhood, all three strategies lead to strikingly similar results, especially in the first years after delivery. The imprecise estimates, evoked by the small number of women who are observed before and some time after childbirth, are also the most likely explanation why the point estimates of the different approaches diverge slightly in later years. 
The figure shows that prospective mothers are happier compared to non-mothers one year before childbirth. The maximum life satisfaction difference between mothers and non-mothers is reached in the year of delivery: the effect is then over half a satisfaction point. The point estimates lie between 0.52 and 0.56 (see Table B1). This is a substantial effect compared to the influence of other standard variables in happiness regressions. For instance, it is higher than the effect of unemployment for women (Clark et al., 2008a) and it is twice the life satisfaction difference that we find between divorced and married women in model (3). However, even in the fixed effects regression, which gives the most precise estimates, only the coefficients capturing the effects during the year of birth and one year before and after birth are individually significant at the $5 \%$ level. The difference in life satisfaction between mothers and non-mothers diminishes with age of the first born child, a sign of adaptation. However, Figure 5 also indicates that the effect of motherhood remains positive over the whole period of 12 years depicted in the figure. In fact, Table B1 confirms that all the coefficients up to year 20 are positive. Moreover, the hypothesis that motherhood has no effect on life satisfaction, thus that all coefficients are equal to zero, is clearly rejected by an F-test. The question then is whether the positive effect is driven by the huge effects occurring only around the birth of the first child or whether motherhood is beneficial over longer periods. To assess this question we tested with an F-test the joint significance of increasing sets of coefficients from the fixed effect specification, excluding the ones that are individually statistically significant. ${ }^{19} \mathrm{Up}$ to year 12 the effect remains strongly significant. The corresponding test statistic is 2.3 ( $\mathrm{p}$-value 0.008 ), and thus provides evidence that up to the onset of teenage years motherhood has a positive and statistically significant effect on life satisfaction.

The motherhood effect can be put into pecuniary terms. With knowledge of the discount factor in the intertemporal utility function it is possible, in principle, to compute the equivalent amount of household income which makes women indifferent between motherhood and childlessness. We use discount factors of $0.95,0.9$ and 0.8 to calculate the net present value of motherhood. Estimates of discount factors found in the literature vary considerably (Frederick et al., 2002). Our first two discount factors lie in the upper half of the range reported in recent field studies. Discount factors obtained experimentally are typically lower, which is reflected in the third choice.

To calculate the net present value we computed in a first step the amount of money which would equalize the happiness levels of mothers and non-mothers with the same covariates. We calculated such an amount for each year after pregnancy. In a second step, we discounted these values and summed them up. The following equations illustrate these steps:

$$
\begin{array}{r}
{\left[\left(i n c+\Delta i n c_{t}\right)-i n c\right] \hat{\delta}_{i n c}+\left[\left(i n c+\Delta i n c_{t}\right)^{2}-i n c^{2}\right] \hat{\delta}_{i n c^{2}}=\hat{\beta}_{t}} \\
\Delta I N C=\sum_{t=0}^{21} \kappa^{t} \Delta i n c_{t}
\end{array}
$$

The amount of money which equalizes the happiness levels in a given period is denoted by $\Delta i n c_{t}$. Since income has a quadratic effect in our model, this amount depends on the level of income (inc).

\footnotetext{
${ }^{19}$ That is, the coefficients corresponding to years $-1,0$, and 1 . To be conservative, we also excluded year 2 , which is individually significant on the $10 \%$ level.
} 
Table 2: Estimated net present value of motherhood (in Net yearly household inCOMES, EVAluated at THE MEAN household income)

\begin{tabular}{lcccccccc}
\hline & \multicolumn{3}{c}{ Model (3) } & & \multicolumn{3}{c}{ Model (4) } \\
\cline { 2 - 5 } \cline { 7 - 8 } Years after birth: & 1 year & 12 years & 20 years & & 1 year & 12 years & 20 years \\
\hline$\kappa=0.80$ & 0.83 & 0.99 & 1.01 & & 0.89 & 1.03 & 1.04 \\
$\kappa=0.90$ & 1.00 & 1.33 & 1.48 & & 1.07 & 1.32 & 1.36 \\
$\kappa=0.95$ & 1.09 & 1.57 & 1.94 & & 1.16 & 1.50 & 1.60 \\
\hline
\end{tabular}

Notes: $\kappa$ is the discount factor. Estimates in columns labeled Model (3) and (4) use estimated coefficients for motherhood from model (3) and model (4), respectively. Coefficients for household income used to estimate the compensating variation is obtained from model (3). Columns 1, 12 and 20 years indicate that coefficients up to 1,12 and 20 years after birth have been added up to compute the net present value of motherhood.

We computed the net present value at the median income. The coefficients for the income effect $\left(\delta_{\text {inc }}\right.$ and $\left.\delta_{i n c^{2}}\right)$ are estimated by model (3) and the motherhood coefficients $\left(\beta_{t}\right)$ are obtained from our specifications with fixed effects (4) and with lags (3). Taking the discount factor $\kappa$ into account, we can compute the net present value $\triangle I N C$.

Table 2 shows the estimated net present values for the three discount rates, different lengths of time, as well as different models - models (3) and (4). For the median woman, motherhood in the period between pregnancy and first child's first birthday (therefore one year after birth) is worth between 0.83 and 1.16 yearly incomes, depending on the point estimates and the discount rates. If one takes the first twelve years into account, the net present value lies between 0.99 and 1.57 yearly household incomes. The whole motherhood effect is worth between 1.01 and 1.94 yearly incomes. These estimates seem reasonable. For instance, couples' willingness to pay for expensive assisted fertility treatments suggest that expected utility gains from motherhood need to be substantial. ${ }^{20}$ Another indication of children's high value to parents, happiness losses caused by the death of a child have been valued at similarly high magnitudes (Oswald \& Powdthavee, 2008).

\subsection{Comparison to previous approaches}

Previous studies which looked at the association between children and life satisfaction have found mostly a negligible or negative motherhood effect. To see whether our results are driven by our special sample restrictions or, as we believe, by the different identification strategy we replicate regressions as they are typically found in the literature with the samples used in this study. Thus, motherhood is identified through a dummy variable indicating the presence of at least one child in the household; and contemporaneous realizations for all control variables are employed. For all samples a regression with

\footnotetext{
${ }^{20}$ Cost-effectiveness studies estimate the cost of live birth at about USD 50,000 (in year 2002 prices; cf. Collins, 2002). In Germany, a part of assisted fertility treatment costs are covered by health insurance. However, there are substantial further non-pecuniary costs such as emotional stress and health risks associated with assisted fertility treatments (Gumus \& Lee, 2012).
} 
Table 3: Estimates of SATISFACTiOn Gains of MOTHERHood USING STANDARD APPROACHES FROM THE LITERATURE

\begin{tabular}{|c|c|c|c|c|c|c|}
\hline \multirow{3}{*}{ Child dummy } & \multicolumn{2}{|c|}{ Transition sample } & \multicolumn{2}{|c|}{ FE sample } & \multicolumn{2}{|c|}{ GSOEP } \\
\hline & -0.036 & -0.104 & -0.004 & -0.015 & 0.028 & -0.044 \\
\hline & $(0.091)$ & $(0.069)$ & $(0.052)$ & $(0.043)$ & $(0.035)$ & $(0.030)$ \\
\hline Individual FE & No & Yes & No & Yes & No & Yes \\
\hline Number of obs. & \multicolumn{2}{|c|}{25,910} & \multicolumn{2}{|c|}{78,470} & \multicolumn{2}{|c|}{198,016} \\
\hline Number of individuals & \multicolumn{2}{|c|}{1,590} & \multicolumn{2}{|c|}{9,791} & \multicolumn{2}{|c|}{22,510} \\
\hline
\end{tabular}

Notes: Cluster-robust standard errors in parenthesis. The regressions additionally include the following control variables: married, boyfriend, single, second order polynomials of weekly working hours and household income and full sets of dummies for age, education, number of household members and years in panel.

and without fixed effects is estimated, corresponding to the traditional frameworks (i) and (ii). Table 3 reports the results from estimating such a life satisfaction model. The first two columns with heading "Transition sample" contain the estimates for the sample which was used for the matching approach (2) and the regression with controls for past satisfaction (3). Column three and four ("FE sample") present the results with observations used in the fixed effects regression (4). The last two columns ("GSOEP") present results using all women that have participated at least once in the GSOEP.

Five out of six estimates are negative and all of them are insignificant, regardless whether fixed effects are included or not. Thus, the standard frameworks (i) and (ii) are unable to detect the positive effects of motherhood, which are clearly present when accounting for dynamic selection.

A comparison of our approach with the event study framework (iii) is given in Figure 6. The solid line reprints our FE regression estimates from Figure 5, while the dashed and solid lines mimic event study regressions that can be found in the literature. The dashed line represents a regression without any anticipation dummies, while the dotted line includes anticipation dummies for three years and uses two years (year -4 and -5 ) to estimate a baseline. Specifically, these two specifications correspond to some of the specifications used in Clark et al. (2008a) (dashed line) and Myrskylä \& Margolis (2014) (dotted line), respectively. While for both these specifications the effect in the year of birth is visible, it is only about half the size of the one found with the estimates of equation (4). The effect is essentially zero the first year after birth, and it even dips slightly below the zero line the following three years. ${ }^{21}$ These different findings are exactly what one would expect if dynamic selection is present but only one approach fully accounts for it. The fact that the methods based on comparing mothers with non-mothers give very similar results (Figure 5) lends additional credibility to our estimates. ${ }^{22}$

The point estimates and standard errors for these estimates can be found in Table B2 in Appendix B.

\footnotetext{
${ }^{21}$ These results are very similar to the ones in the original papers. In addition, the Myrskylä \& Margolis (2014) specification also includes an estimate for the effect in the following ten years. In their paper as well as in our implementation of their specification this effect is virtually zero.

${ }^{22}$ The specifications of Myrskylä \& Margolis (2014) and Clark et al. (2008a) use only the within-estimator.
} 
Figure 6: ESTIMATES OF SATISFACTION GAINS OF MOTHERHOOD USING STANDARD APPROACHES FROM THE LITERATURE

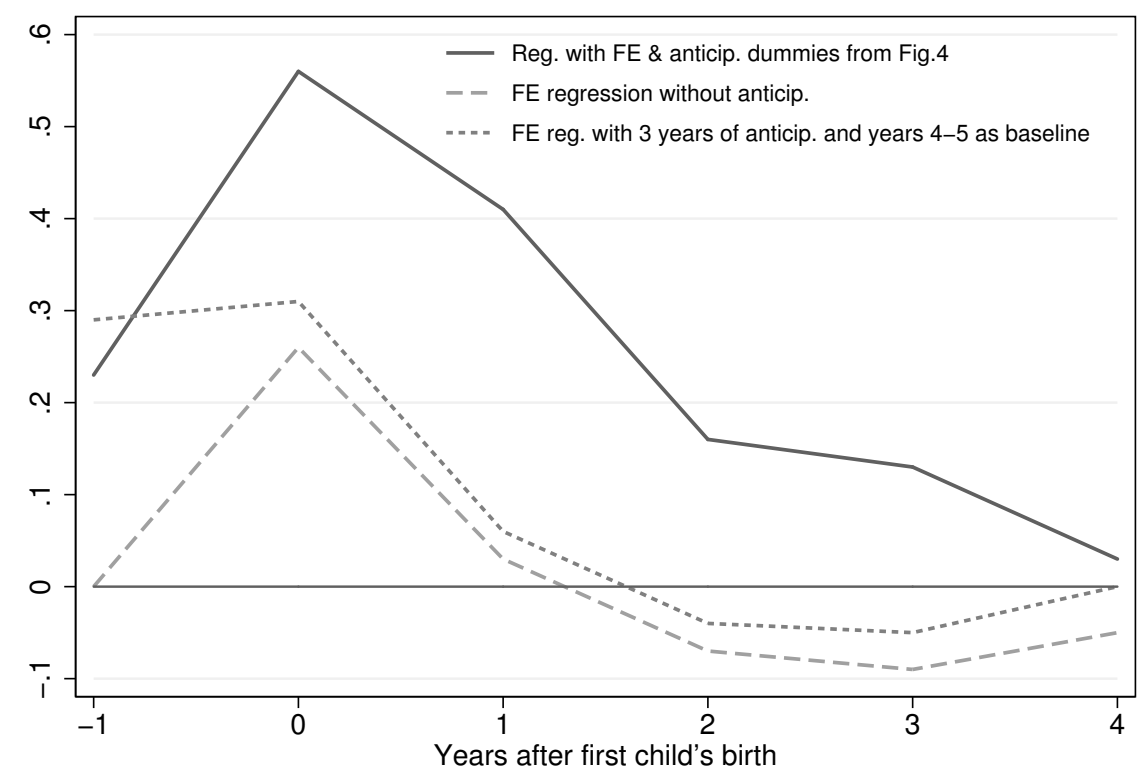

Notes: The solid line reproduces the coefficients estimates corresponding to equation (4) and also depicted in Figure 5. Estimates and standard errors for the dashed and dotted lines are given in Table B2.

Taken together, Table 3 and Figure 6 illustrate the difference that accounting for dynamic selection can make in shifting the profile of the satisfaction profile upwards and therefore allowing to uncover satisfaction gains.

\subsection{Extensions}

We extend our analysis in different directions. First, we examine whether mother's age at first birth affects satisfaction gains obtained from motherhood. Then, we study if motherhood status captures the main effect of the fertility decision on life satisfaction or if one should focus on the number of children. Finally, we explore the effect of fatherhood on life satisfaction. Except where noted otherwise, we use the fixed effect specification in this section.

\section{Age at first birth}

Figure 7 shows the effect of motherhood on life satisfaction depending on mother's age at first birth (AFB in the figure). For comparison, the thick line depicts again the average effect for all mothers presented earlier in Figure 5. The effects for different groups of age-at-first-birth are shown by the thin lines. The youngest group, for example, consists of mothers giving birth to their first child between the age 26 and 29. Looking at younger mothers is difficult, because six pre-birth observations are needed to allow for individual-specific fixed effects and an anticipation period of five years. The oldest group consists of women with first delivery between 35 and 37. The different group lines are smoothed to 
Figure 7: Estimated LIFE SATISFACTION GAINS OF MOTHERHOOD FOR DIFFERENT AGE-AT-FIRSTBIRTH (AFB) GROUPS - FE REGRESSION

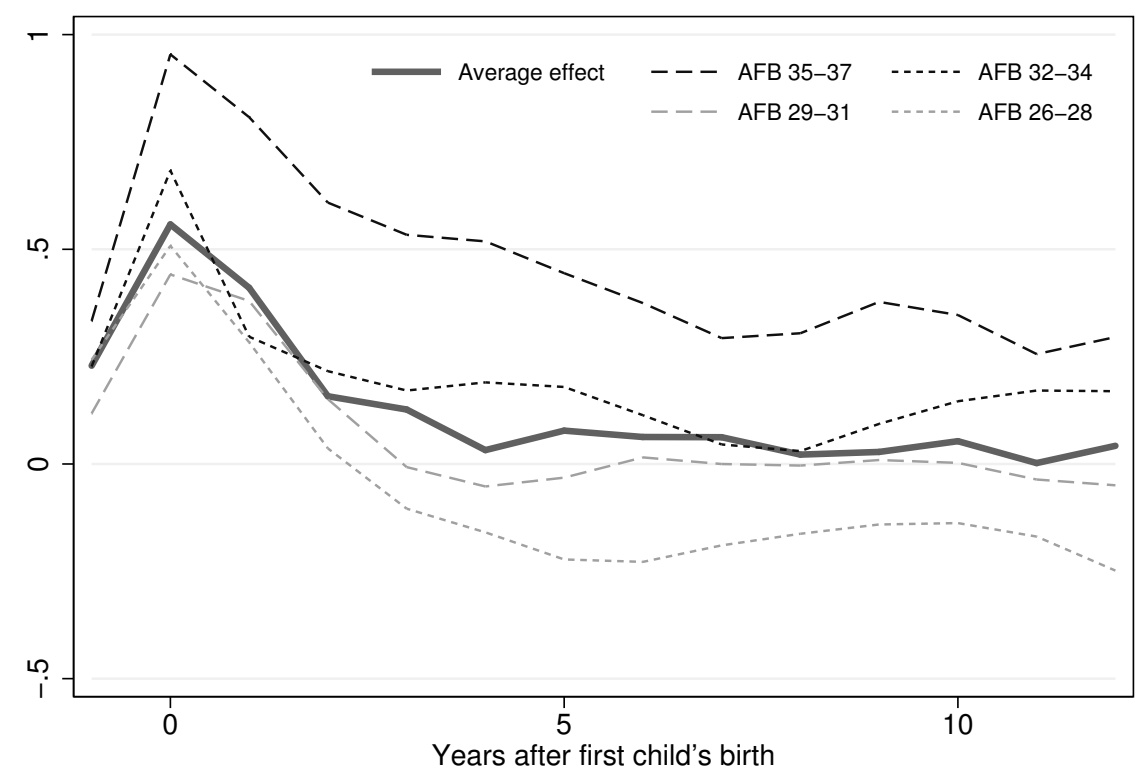

Notes: The thick line shows again the average motherhood effect ( $\beta$ in model 4$)$ from Figure 5. The thin lines show the estimated motherhood effect of model (4) interacted with age at first birth. All regressions include four extra dummies for minus two to minus five years before first birth. The data is introduced in Appendix A5. Thin lines smoothed (Lowess) with bandwidth 0.15 .

present a visually clearer picture.

The horizontal order of the four lines suggests that the motherhood effect is larger for women having a child later in life. ${ }^{23}$ The lines of the two younger groups are below the average line and the curves for the two older groups above. The oldest category have clearly the largest happiness gains. The youngest mothers, on the other hand, seem to be the only group of mothers that suffer from the motherhood status, at least in later years. In general, the pregnancy effect seems higher for older groups than for younger groups, but one has to be cautious with interpreting the results. If only the difference in the happiness levels directly before and after delivery is considered, the women in the oldest category still profit most and the youngest mothers fewest, but the ranking of the middle groups is less clear.

\section{Single-child and multiple-parity mothers}

Figure 8 shows the effect of motherhood on life satisfaction for single-child mothers and mothers giving birth to several children in the observation period. One could hypothesize that a large positive satisfaction gain from the first child leads to a higher likelihood of having additional children. However, as can be seen from the figure, effects for mothers of several children are strikingly similar to those of mothers of a single child a year around childbirth. Therefore we have not found any evidence for such a hypothesis. The differences in life satisfaction levels between the two categories of mothers

\footnotetext{
${ }^{23}$ There are several possible channels which might explain such a pattern. For instance, later timing of first birth is associated with higher wage growth (Herr, 2007).
} 
Figure 8: Estimated LIFE SATISFACTION GAins OF MOTHERHOOD FOR Single-ChILD AND MULTIPLE-PARITY MOTHERS - FE REGRESSION

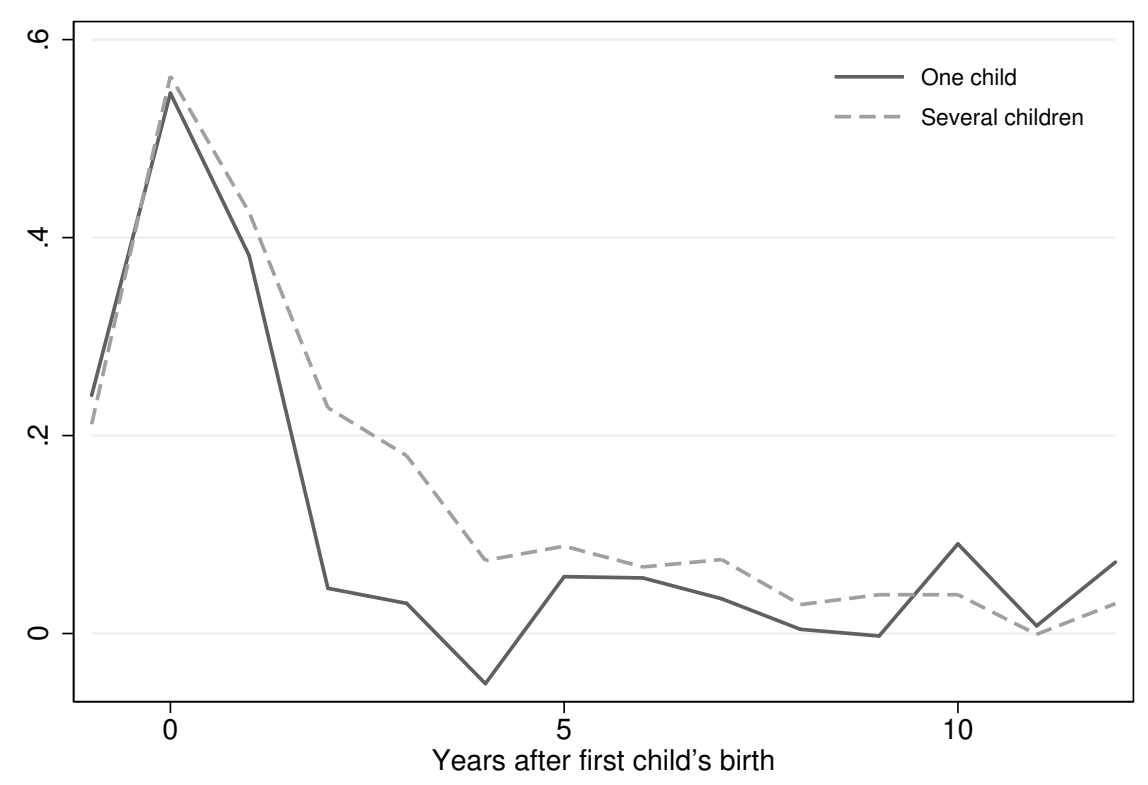

Notes: The lines show the estimated motherhood effect of model (4) interacted with a variable indicating if the mother has one child, or more than one child over her life span. All regressions include four extra dummies for minus two to minus five years before first birth. The data is introduced in Appendix A5.

and non-mothers are also small from five years after delivery on. In between, however, multiple-parity mothers report higher happiness levels on average. The reason is probably the additional birth taking place during this period. We also looked at the effect of the second child, and the results (not shown) support this interpretation. In about seventy percent of all cases, the time span between birth of the first and second child amounts to four years or less ${ }^{24}$, and the effect of the second child is also positive with a peak at childbirth, albeit the effect is only about half as large as the effect caused by the first child's birth. All in all, these results suggest that the main event or decision in a life of a mother is birth of the first child and the related issue of starting a family. The intensive margin of fertility, number of children, seems less important for the overall evolution of mothers' life satisfaction paths.

\section{Fatherhood}

For men, it is more difficult to find an appropriate age threshold for defining men's completed fertility as their distribution of age at first birth exhibits a noticeably longer tail than women's. Again the empirical distribution of age at first birth was used to determine the maximum age at first birth (47 years). ${ }^{25}$

Figure 9 shows the effect of fatherhood. The results are similar to those of motherhood; however, the effect before and at birth seem a bit smaller. Whereas the effect of motherhood in the first year after birth was estimated to be about 0.55 points, the effect of fatherhood is about 0.45 . The fixed

\footnotetext{
${ }^{24}$ The average spell between the first and second birth is 2.3 years in Germany (Statistisches Bundesamt, 2012).

${ }^{25}$ Until the age of $48,99.8 \%$ of fathers have had their first child. Appendix A6 depicts the estimation sample in detail.
} 
Figure 9: Estimated life SATiSfaction (LS) Gains of FATHERHood

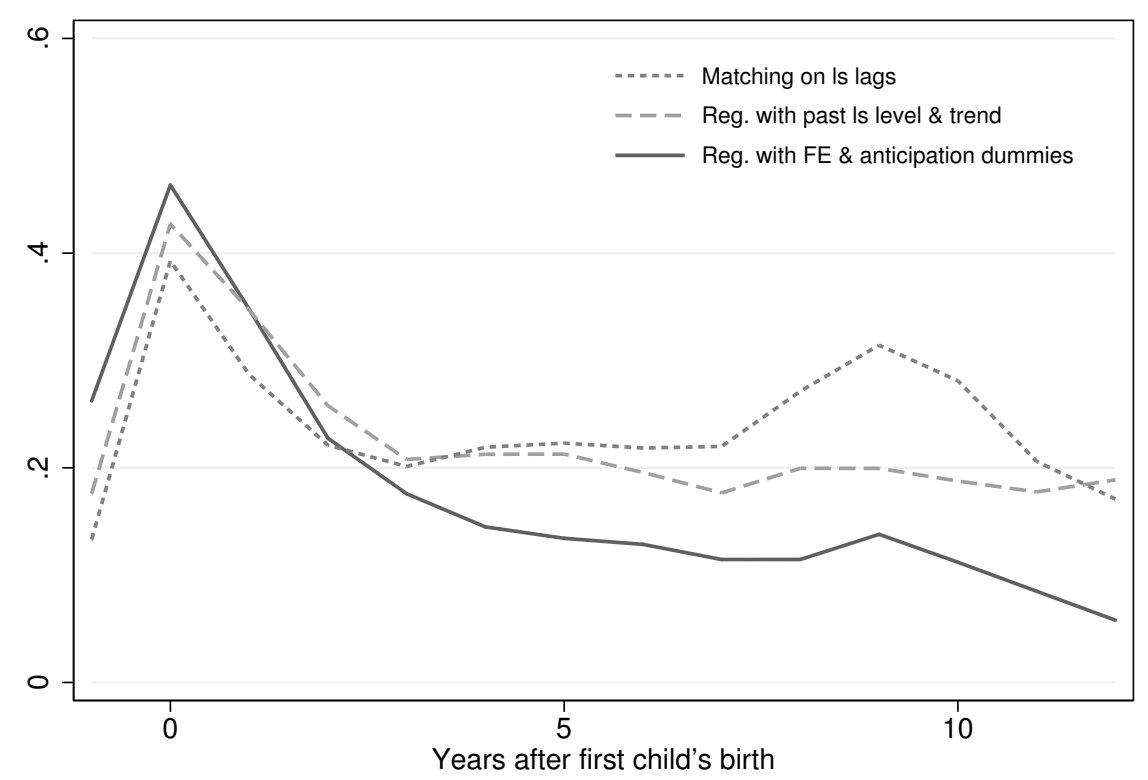

Notes: The lines show the fatherhood effect estimated with different approaches. Notes to estimation approaches can be found in Figure 5. The data is introduced in Appendix A6. All lines smoothed (Lowess) with bandwidth 0.15 .

effects estimator shows a clear decline after two years, stabilizing at around 0.1 for the next twenty years, while the matching estimator and the regression with past satisfaction level and trend suggest a somewhat slower decline. Thus, both men and women seem to derive satisfaction from having a child.

\section{Discussion}

This paper examined how becoming a mother affects women's life-cycle satisfaction by using panel data from the GSOEP. We identified family ties in order to define mothers and non-mothers, and built a completed fertility decision sample in order to overcome censoring of future mothers. A hallmark of our approach is that we looked extensively at the pre-birth period, i.e. selection into motherhood, comparing mothers to non-mothers, and distinguishing between planned and unplanned pregnancies. We found that initially mothers and non-mothers do not differ in terms of their satisfaction trajectories. However, trajectories start diverging as much as five years prior to a prospective mother's first birth. We discussed the implications of this finding of dynamic selection into motherhood for the three most commonly used empirical frameworks in the literature, and concluded that for all three it should lead to an underestimation of the motherhood effect. Using the insights from our findings on selection, we proposed two estimation strategies that address this issue by defining appropriate control groups. The first approach uses as the control group non-mothers that experienced a similar increasing life satisfaction trajectory than mothers during the selection period before first birth. The second approach uses as the control group observations of the mothers before they entered the selection period.

Our estimations yielded similar results from both approaches, indicating that there are substantial 
satisfaction gains from motherhood from one year before to one year after birth. The effects decrease after that, but remain positive and statistically significant for as much as twelve years after the first birth. The effects are larger for mothers who are older at first birth. The results are robust to various specifications and consequently confirm the importance of accounting for selection issues. Moreover, our estimates contrast with those we would obtain applying the methods used in the previous literature in that we uncover positive effects of motherhood where zero or only attenuated and very transitory effects would be found. More generally, our findings can be seen as broadly in line with a mainstream view of choice behavior based on utility maximization.

Obviously, the utility gains from motherhood are specific to social, technological and other factors. The women surveyed in the German Socio-Economic Panel live in a modern society and a historical moment where birth control is effective, widely available and its use socially accepted; there is universal health care access and the law stipulates extended maternity leaves. Thus, such an environment is probably particularly conducive to large satisfaction gains from motherhood.

\section{References}

[1] Abadie, Alberto, David Drukker, Jane Leber Herr, \& Guido W Imbens, 'Implementing matching estimators for average treatment effects in Stata.' Stata Journal, 4, pp. 290-311, 2004.

[2] \& \& Guido ImBens, 'Simple and bias-corrected matching estimators for average treatment effects.' National Bureau of Economic Research Technical Report No. 283, 2002.

[3] Alesina, Alberto, Rafael Di Tella, \& Robert MacCulloch, 'Inequality and happiness: are Europeans and Americans different?' Journal of Public Economics, 88 (9), pp. 2009-2042, 2004.

[4] Arroyo, Cristino R \& Junsen Zhang, 'Dynamic microeconomic models of fertility choice: A survey.' Journal of Population Economics, 10 (1), pp. 23-65, $199 \%$.

[5] Becker, Gary S, 'An economic analysis of fertility.' In Demographic and economic change in developed countries: Columbia University Press, pp. 209-240, 1960.

[6] Benjamin, Daniel J, Miles S Kimball, Ori Heffetz, \& Alex Rees-Jones, 'What do you think would make you happier? What do you think you would choose?' American Economic Review, 102 (5), p. 2083, 2012.

[7] Blanchflower, David G, 'International evidence on well-being.' In Alan Bennett Krueger ed. Measuring the subjective well-being of nations: National accounts of time use and well-being: University of Chicago Press, pp. 155-226, 2009.

[8] Clark, Andrew E, 'Born to be mild? Cohort effects don't (fully) explain why well-being is U-shaped in age.' IZA Discussion Paper, $200 \%$.

[9] _ E E E _ Ehard Diener, Yannis Georgellis, \& R E Lucas, 'Lags and leads in life satisfaction: a test of the baseline hypothesis.' Economic Journal, 118, pp. F222-243, 2008 a.

[10] _ Paul Frijters, \& Michael A Shields, 'Relative income, happiness, and utility: An explanation for the Easterlin paradox and other puzzles.' Journal of Economic Literature, pp. 95-144, $2008 b$.

[11] _ \& Yannis Georgellis, 'Back to baseline in Britain: adaptation in the British household panel survey.' Economica, 80 (319), pp. 496-512, 2013.

[12] _ \& Andrew J Oswald, 'Unhappiness and unemployment.' Economic Journal, pp. 648-659, 1994.

[13] _ _ \& , 'Well-being in panels.' DELTA, mimeo, 2002.

[14] Collins, John A, 'An international survey of the health economics of IVF and ICSI.' Human Reproduction Update, 8 (3), pp. 265-277, 2002. 
[15] Boca, Daniela Del \& Marilena Locatelli, 'The determinants of motherhood and work status: A survey.' IZA Discussion Paper, 2006.

[16] Tella, Rafael Di, Robert J MacCulloch, \& Andrew J Oswald, 'Preferences over inflation and unemployment: Evidence from surveys of happiness.' American Economic Review, 91, pp. 335-341, 2001.

[17] _ _ _ _ _ , 'The macroeconomics of happiness.' Review of EconSSomics and Statistics, 85 (4), pp. 809-827, 2003.

[18] Dolan, Paul, Tessa Peasgood, \& Mathew White, 'Do we really know what makes us happy? A review of the economic literature on the factors associated with subjective well-being.' Journal of Economic Psychology, 29 (1), pp. 94-122, 2008.

[19] Easterlin, Richard A, 'Does money buy happiness?' The Public Interest, 30, p. 3, 1973.

[20] _ _ 'Income and happiness: Towards a unified theory.' Economic Journal, pp. 465-484, 2001.

[21] Ferrer-i-Carbonell, Ada, 'Happiness economics.' SERIEs, 4 (1), pp. 35-60, 2013.

[22] Frederick, Shane, George Loewenstein, \& Ted O'donoghue, 'Time discounting and time preference: A critical review.' Journal of Economic Literature, pp. 351-401, 2002.

[23] Frey, Bruno S \& Alois Stutzer, 'What can economists learn from happiness research?' Journal of Economic Literature, pp. 402-435, 2002.

[24] Frijters, Paul, David W Johnston, \& Michael A Shields, 'Life Satisfaction Dynamics with Quarterly Life Event Data.' Scandinavian Journal of Economics, 113 (1), pp. 190-211, 2011.

[25] Gilbert, Daniel, 'Stumbling onto happiness.' New York, 2006.

[26] Gumus, Gulcin \& Jungmin Lee, 'Alternative paths to parenthood: IVF or child adoption?' Economic Inquiry, 50 (3), pp. 802-820, 2012.

[27] Hansen, Thomas, 'Parenthood and happiness: A review of folk theories versus empirical evidence.' Social Indicators Research, 108 (1), pp. 29-64, 2012.

[28] Herbst, Chris M \& John Ifcher, 'The Increasing Happiness of Parents.' Review of the Economics of the Household, 2015, forthcoming.

[29] Herr, Jane Leber, 'Does it pay to delay? Understanding the effect of first birth timing on women's wage growth.' University of California-Berkeley Working Paper, $200 \%$.

[30] Kahneman, Daniel, Edward Diener, \& Norbert Schwarz, Well-being: Foundations of hedonic psychology: Russell Sage Foundation, 1999.

[31] Kohler, Hans-Peter, Jere R Behrman, \& Axel Skytthe, 'Partner+ Children= Happiness? The Effects of Partnerships and Fertility on Well-Being.' Population and Development Review, 31 (3), pp. 407-445, 2005.

[32] Layard, Richard, 'Happiness: lessons form a New Science.' London: Allen Lane, 2005.

[33] MA, BInG, 'The occupation, marriage, and fertility choices of women: A life-cycle model.' Working Paper, UMBC Department of Economics, 2010.

[34] Michaud, Pierre-Carl \& Konstantinos Tatsiramos, 'Fertility and female employment dynamics in Europe: the effect of using alternative econometric modeling assumptions.' Journal of Applied Econometrics, 26 (4), pp. 641-668, 2011.

[35] Morgan, S Philip \& Rosalind Berkowitz King, 'Why have children in the 21st century? Biological predisposition, social coercion, rational choice.' European Journal of Population/Revue européenne de Démographie, 17 (1), pp. 3-20, 2001.

[36] Myrskylä, Mikko \& Rachel Margolis, 'Happiness: Before and after the kids.' Demography, 51 (5), pp. 1843-1866, 2014.

[37] Oswald, Andrew J \& Nattavudh Powdthavee, 'Death, happiness, and the calculation of compensatory damages.' Journal of Legal Studies, 37 (S2), pp. S217-S251, 2008.

[38] StancA, LucA, 'Suffer the little children: Measuring the effects of parenthood on well-being worldwide.' Journal of Economic Behavior \& Organization, 81 (3), pp. 742-750, 2012. 
[39] Statistisches Bundesamt, 'Geburten in Deutschland.' Wiesbaden: Bestellnummer 012000\%-12900-1, 2012.

[40] Stevenson, Betsey \& Justin Wolfers, 'Economic Growth and Subjective Well-Being: Reassessing the Easterlin Paradox.' Brookings Papers on Economic Activity, 2008.

[41] Stutzer, Alois \& Bruno S Frey, 'Does marriage make people happy, or do happy people get married?' Journal of Socio-Economics, 35 (2), pp. 326-347, 2006.

[42] Landeghem, Bert Van, 'A test for the convexity of human well-being over the life cycle: Longitudinal evidence from a 20-year panel.' Journal of Economic Behavior $\& 3$ Organization, 81 (2), pp. 571-582, 2012.

[43] Vanassche, Sofie, Gray Swicegood, \& Koen Matthijs, 'Marriage and children as a key to happiness? Crossnational differences in the effects of marital status and children on well-being.' Journal of Happiness Studies, 14 (2), pp. 501-524, 2013.

[44] Veenhoven, Ruut, 'Healthy happiness: Effects of happiness on physical health and the consequences for preventive health care.' Journal of Happiness Studies, 9 (3), pp. 449-469, 2008.

[45] Wilde, Elizabeth Ty, Lily Batchelder, \& David T Ellwood, 'The mommy track divides: The impact of childbearing on wages of women of differing skill levels.' National Bureau of Economic Research Working Paper No. 16582, 2010.

[46] Willis, Robert J, 'A new approach to the economic theory of fertility behavior.' Journal of Political Economy, pp. S14-S64, 1973.

[47] Winkelmann, Rainer \& Liliana Winkelmann, 'Why are the unemployed so unhappy? Evidence from panel data.' Economica, 65, pp. 1-15, 1998.

[48] Wunder, Christoph, Andrea Wiencierz, Johannes Schwarze, \& Helmut Küchenhoff, 'Well-being over the life span: Semiparametric evidence from British and German longitudinal data.' Review of Economics and Statistics, 95 (1), pp. 154-167, 2013.

\section{Appendix A Data}

We use data from the German Socio Economic Panel (GSOEP). The GSOEP exhibits at least three features that benefit the analysis of motherhood. First, person pointers identify a respondent's mother and children. Second, we have access to 26 yearly waves, starting in 1984 . This permits us to identify women with fertility equal to zero over their entire life, but to observe these non-mothers during possibly fertile years. Third, information on the type of pregnancy (planned or unplanned) is available from a special mother and child questionnaire for the subset of mothers with year of first birth 2002 or later.

Appendix A0 shortly documents how different variables were constructed and how they were integrated as control variables in the regressions. Appendices A1 to A6 describe the subsamples generated from the GSOEP for this study's analyses. Means of selected variables are depicted in Table A.

\section{A0 Variables used}

Original variable names as they appear the first time in the GSOEP are reported in parentheses. Household (ahhnr) and never changing person numbers (persnr) identify households and individuals. Pointers to person numbers define a respondent's mother (mnr, akmutti, bymnr or persnrm), father (byvnr, vnr) and children (kidpnr or idperschild). The dependent variable, life satisfaction, was 
assessed by asking respondends: "In conclusion, we would like to ask you about your satisfaction with your life in general. Please answer according to the following scale: 0 means completely dissatisfied, 10 means completely satisfied. How satisfied are you with your life, all things considered?" (p1110184). Birth year (gebjahr) was used together with survey year to construct age. Exact ages of a mothers' children were computed through birth dates of a child (kidmon, kidgeb) and interview dates of a mother (bpmonin, ahtagin). Years in panel was generated from the number of a respondents' observations in our data.

In all estimations presented in this study, complete sets of indicator variables control for age, survey year and number of years in panel. Estimates controlling for socioeconomic factors include the following set of variables: seven dummies categories of completed education (apsbil) (secondary school degree, intermediate school degree, technical school degree, upper secondary degree, other degree, dropout, no school degree yet); three dummies for relationship (ap58) married, having a partner but not married, single; complete set of dummies for numbers of household members (ahhgr); a second order polynomial for weekly hours worked (atatzeit) that range from 0 to 80; a dummy indicating whether hours were reported (58\%) or not; household income (hinc84) and household income squared for monthly salaries between 0 and 100,000 Euros and a dummy for reported household income (95\%). Moreover, for the pre-birth period analysis the dummy variable planned pregnancy (bcssplan) is used.

\section{A1 Life cycle sample}

The life cycle analyses include all observations on non-mothers with a fertility of zero at age 41 and on mothers with age of first birth equal to 28 years, aged 20 to 80 during waves 1984 to 2009 and reporting valid answers to the questions in this study. This yields 25,773 observations for 3,885 women.

\section{A2 Pre-birth completed fertility sample}

The pre-birth analysis contrasts pre-birth life satisfaction of mothers-to-be to that of similar nonmothers. Given a threshold of 41 years for a completed fertility decision by the age of 41 , prospective mothers are younger than 41 years. This maximum age is imposed on non-mothers' ages, too. This implies that non-mothers are born before 1968. In return, this cohort restriction is applied to mothers' birth cohorts. Moreover, for pre-birth analyses exact ages of respondents' offspring were used. These restrictions leave 5,756 observations for 947 women.

\section{A3 Pre-birth "birth-type" sample}

The GSOEP mother and child questionnaire is in field since 2003 and covers new mothers from 2002 on. Out of 1,249 new mothers who answered the question, $70 \%$ judged that their pregnancy was more planned than unplanned. Due to the questionnaire's inception date, the information is available for mothers aged maximally 46 years in 2009. To obtain a same-aged control group, the completed fertility 
decision sample's non-mothers are replaced by potential non-mothers, i.e. contemporaneously childless women. In order to find the same range of age for both mothers and non-mothers, we impose potential non-mothers not to be born before 1959 and not to exceed the age of 41 . This leaves us with 14,879 observations for 2,572 individuals. For all of these women first child's exact birth date are available.

\section{A4 Transition sample}

Implications of matching or controling on pre-birth life satisfaction are threefold. First, transition into motherhood needs to be observed. This implies that mothers' age cannot exceed 60 years in our sample. We apply this age restriction also to non-mothers. Second, pre-birth observations need to be observed such that controlling or matching on past life satisfaction paths is feasible. For 1,590 women -with 25,910 observations- past satisfaction levels and trends are identified. Third, our analysis considers mothers one year before first child's birth. To find similar, same-aged non-mothers we use all possible ages of non-mothers. This implies that, if possible, non-mothers are "cloned" and used multiple times with covariates measured at the corresponding age. The total number of observations is then 37,616. Cloning induces an obvious dependence between cloned observations. All reported standard errors and test statistics account for arbitrary clustering and heteroskedasticity of any type at the individual level, and therefore account for the dependence between multiple observations of non-mothers.

\section{A5 Fixed effect estimation sample}

Fixed effect regressions estimate the effect of motherhood for women aged 20 to 60 . The GSOEP provides information about 13,652 women whose ages fall into this interval. Again, only women with a completed fertility decision are retained in the sample. We are left with 78,470 observations for 9,791 individuals.

\section{A6 Father sample}

For the analysis of fatherhood valid responses of male participants from GSOEP waves 1984 to 2009 are used. As for women, the age by which the fertility decision is completed is defined by means of the data at hand. Mean and median age of first birth for men are equal to 27 and 28 years. $99.6 \%$ of all fathers had their first child before the age of 48 . We thus define non-fathers as men who have not fathered a child until the age of 48 . The sample consists of 82,261 observations for 8,449 men. 
Table A: Means of Selected variables for different samples

\begin{tabular}{lcccccc}
\hline & A1 & A2 & A3 & A4 & A5 & A6 \\
\cline { 2 - 7 } Proportion parents & 0.35 & 0.52 & 0.35 & 0.81 & 0.90 & 0.93 \\
Age & 51.86 & 30.45 & 27.58 & 31.09 & 34.87 & 39.48 \\
Net-monthly HH-income in Euros & 2137 & 2002 & 2048 & 2201 & 2236 & 2440 \\
Weekly hours worked & 17.64 & 33.69 & 31.10 & 23.38 & 20.15 & 38.06 \\
Proportion high school degrees & 0.19 & 0.25 & 0.33 & 0.23 & 0.18 & 0.19 \\
Proportion school drop outs & 0.03 & 0.02 & 0.02 & 0.03 & 0.04 & 0.03 \\
Proportion married & 0.55 & 0.34 & 0.22 & 0.49 & 0.63 & 0.69 \\
Proportion with partner & 0.16 & 0.36 & 0.54 & 0.29 & 0.18 & 0.15 \\
Proportion single & 0.22 & 0.16 & 0.22 & 0.14 & 0.09 & 0.08 \\
\hline Number of observations & 25,773 & 5,756 & 14,879 & 25,910 & 78,470 & 82,261 \\
Number of individuals & 3,885 & 947 & 2,572 & 1,590 & 9,791 & 8,449 \\
\hline
\end{tabular}

\section{Appendix B Regression Output}

Table B1: Regression Coefficients of Figure 2

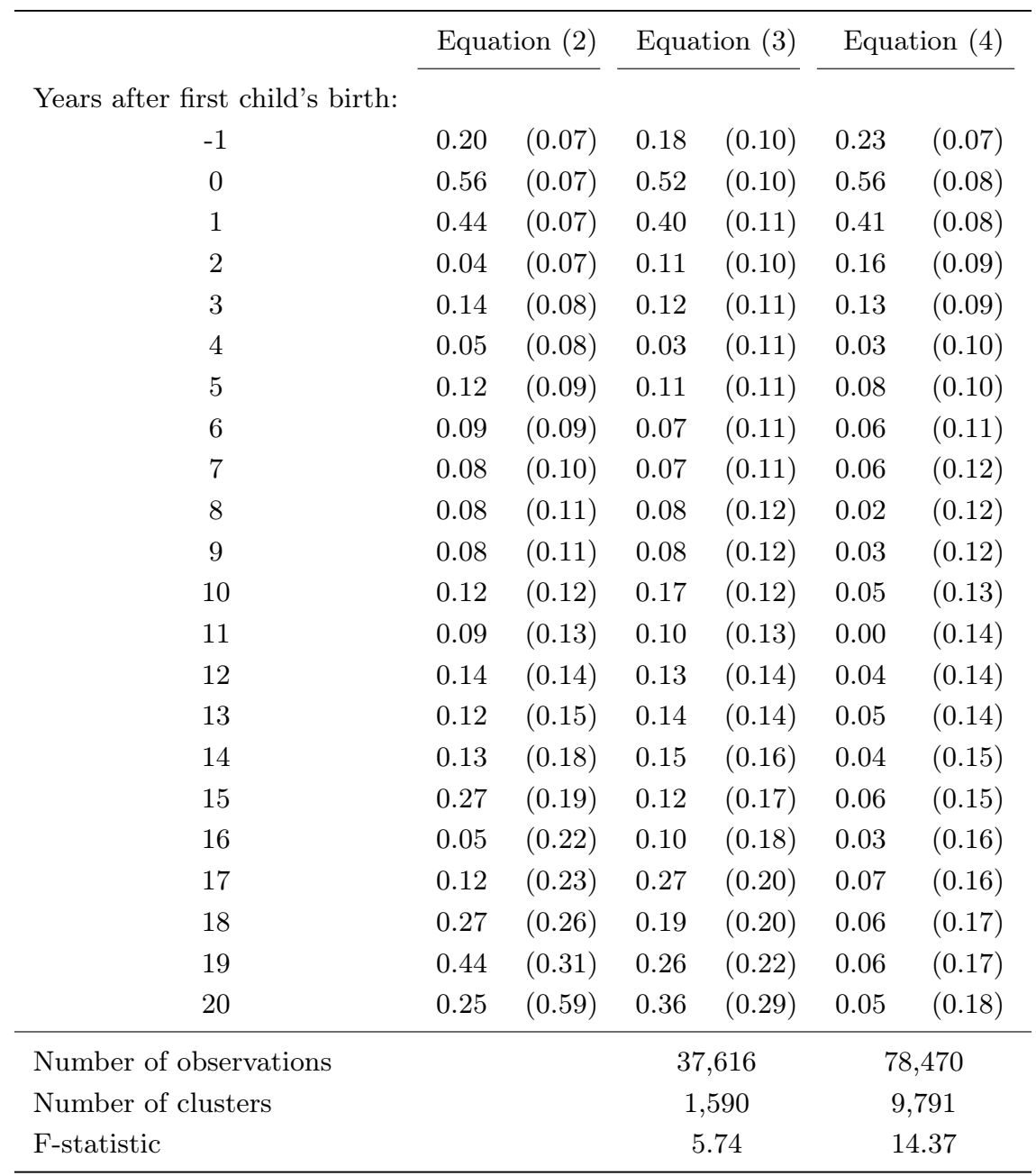

Note: The table shows the point estimates of the motherhood effect for different estimations strategies (equation (2): Matching; equation (3): Regression using past satisfaction levels and trends; equation (4): Fixed effects regression accounting for the anticipation effect). Cluster-robust standard errors in parenthesis. The estimates are graphically presented in Figure 2. F-statistic for the hypothesis that all shown coefficients are equal to zero. The critical value at the $1 \%$ level is 1.85 . 
Table B2: Estimates of SATisfaction gains of Motherhood using STANDARD APproacheS FROM THE LIFE EVENT LITERATURE

(1)

$(2)$

Years after first child's birth:

\begin{tabular}{ccccc}
$-2,-3$ & & & 0.07 & $(0.03)$ \\
-1 & & & 0.29 & $(0.03)$ \\
0 & 0.26 & $(0.02)$ & 0.31 & $(0.03)$ \\
1 & 0.03 & $(0.02)$ & 0.06 & $(0.03)$ \\
2 & -0.07 & $(0.03)$ & -0.04 & $(0.03)$ \\
3 & -0.09 & $(0.03)$ & -0.05 & $(0.03)$ \\
4 & -0.05 & $(0.08)$ & -0.00 & $(0.03)$ \\
$5-9$ & & & -0.00 & $(0.03)$ \\
$10-15$ & & & -0.04 & $(0.03)$ \\
\hline Number of observations & 67,990 & \multicolumn{2}{c}{67,990} \\
Number of clusters & \multicolumn{2}{c}{8,664} & \multicolumn{3}{c}{864} \\
\hline
\end{tabular}

Note: The table shows the point estimates of the motherhood effect for two fixed effects models from the literature. Cluster-robust standard errors in parenthesis. The estimates are graphically presented in Figure 6.

\section{Appendix C - Additional Figures}

Figure C1: WeEKLY WORKING HOURS OVER THE LIFE CYCLE

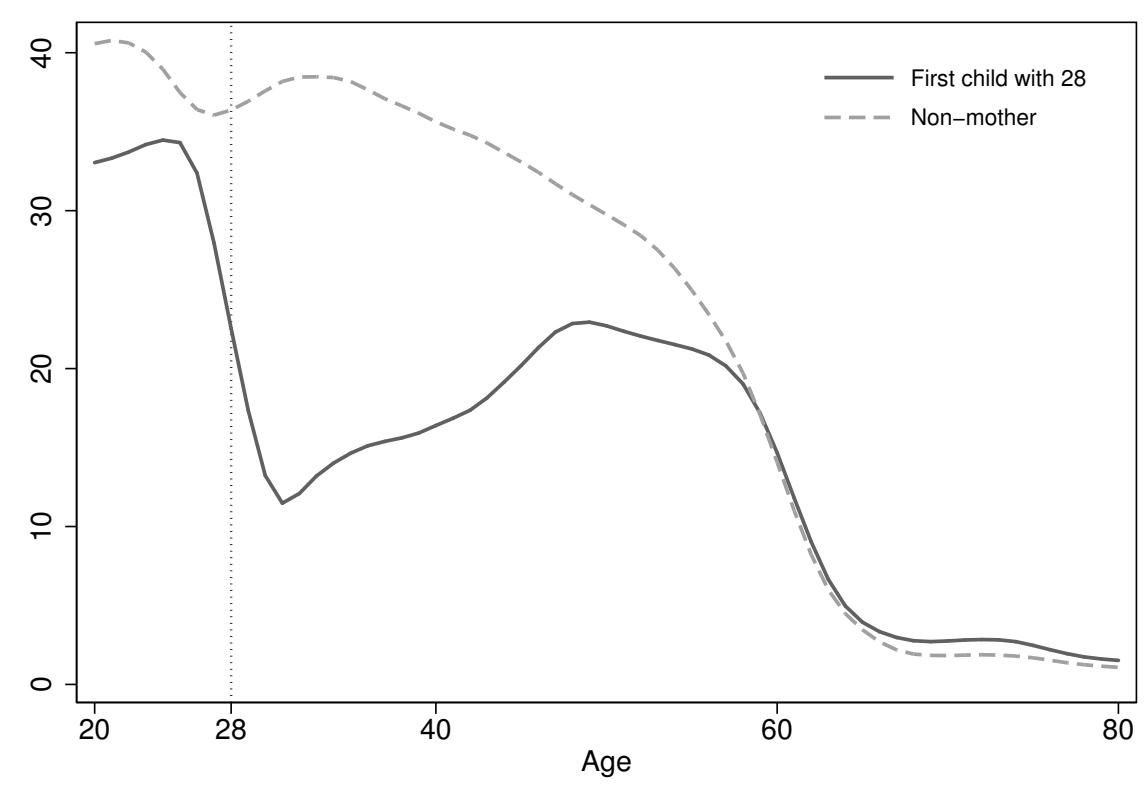

Notes: Data from the GSOEP waves 1984-2009 is detailed in Appendix A1. Displayed average life satisfaction paths are conditional on sets of dummies for survey years and years in panel, smoothed (Lowess) with bandwidth 0.12 . 
Figure C2: Life satisfaction Before Birth: Subsample analysis

High early human capital

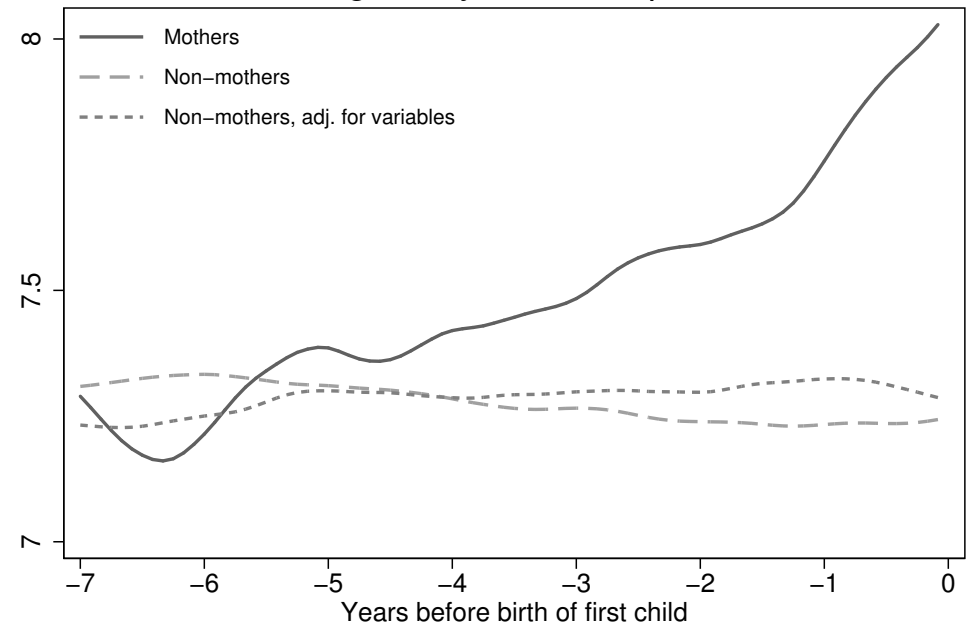

Low early human capital

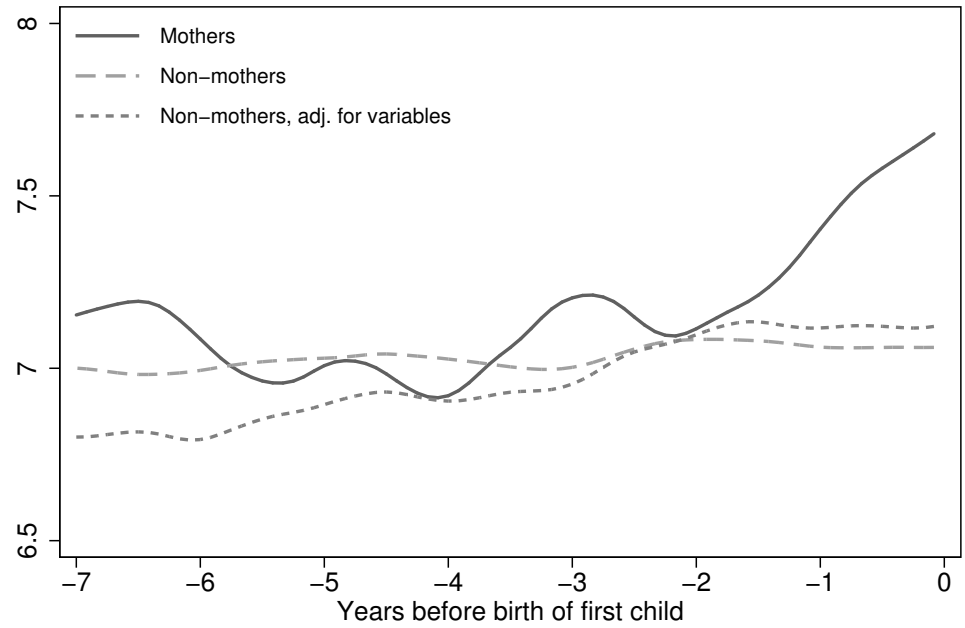

Notes: The graph depicts parameter estimates for the vector of dummy variables months to birth in model (1) for a subset of 7 years. The top panel is based on estimates from the subsample of women who completed either of the two highest secondary school tracks (around $63 \%$ of the whole sample); the lower panel is based on estimates from the subsample of women who did not (around $37 \%$ of the whole sample). The data is detailed in Appendix A2. Displayed average life satisfaction paths are conditional on a full set of dummies for age, survey years and years in panel. Predicted life satisfaction adjusted for variables further includes controls for education, relationship status, household members, working hours and household income. All lines smoothed (Lowess) with bandwidth 0.3. Appendix A0 contains a detailed description of the included terms. 